\title{
Tau is required for progressive synaptic and memory deficits in a transgenic mouse model of a-synucleinopathy
}

\author{
Balvindar Singh ${ }^{1,2} \cdot$ Ana Covelo $^{3} \cdot$ Héctor Martell-Martínez $^{3} \cdot$ Carmen Nanclares $^{3} \cdot$ Mathew A. Sherman $^{3}$. \\ Emmanuel Okematti ${ }^{3}$. Joyce Meints ${ }^{3}$. Peter J. Teravskis ${ }^{3}$. Christopher Gallardo ${ }^{4}$. Alena V. Savonenko ${ }^{9}$. \\ Michael A. Benneyworth ${ }^{3,5,6}$. Sylvain E. Lesné3, ${ }^{3,5,7} \cdot$ Dezhi Liao $^{3,5} \cdot$ Alfonso Araque $^{3,5} \cdot$ Michael K. Lee $^{3,5,8}$ (i)
}

Received: 12 April 2019 / Revised: 27 May 2019 / Accepted: 27 May 2019 / Published online: 6 June 2019

(c) The Author(s) 2019

\begin{abstract}
Parkinson's disease dementia (PDD) and dementia with Lewy bodies (DLB) are clinically and neuropathologically highly related $\alpha$-synucleinopathies that collectively constitute the second leading cause of neurodegenerative dementias. Genetic and neuropathological studies directly implicate $\alpha$-synuclein $(\alpha \mathrm{S})$ abnormalities in PDD and DLB pathogenesis. However, it is currently unknown how $\alpha \mathrm{S}$ abnormalities contribute to memory loss, particularly since forebrain neuronal loss in PDD and DLB is less severe than in Alzheimer's disease. Previously, we found that familial Parkinson's disease-linked human mutant $\mathrm{A} 53 \mathrm{~T} \alpha \mathrm{S}$ causes aberrant localization of the microtubule-associated protein tau to postsynaptic spines in neurons, leading to postsynaptic deficits. Thus, we directly tested if the synaptic and memory deficits in a mouse model of $\alpha$-synucleinopathy (TgA53T) are mediated by tau. TgA53T mice exhibit progressive memory deficits associated with postsynaptic deficits in the absence of obvious neuropathological and neurodegenerative changes in the hippocampus. Significantly, removal of endogenous mouse tau expression in $\operatorname{Tg} \mathrm{A} 53 \mathrm{~T}$ mice $\left(\mathrm{TgA} 53 \mathrm{~T} / \mathrm{mTau}^{--}\right)$, achieved by mating $\mathrm{TgA} 53 \mathrm{~T}$ mice to mouse tauknockout mice, completely ameliorates cognitive dysfunction and concurrent synaptic deficits without affecting $\alpha \mathrm{S}$ expression or accumulation of selected toxic $\alpha \mathrm{S}$ oligomers. Among the known tau-dependent effects, memory deficits in TgA53T mice were associated with hippocampal circuit remodeling linked to chronic network hyperexcitability. This remodeling was absent in $\mathrm{TgA} 53 \mathrm{~T} / \mathrm{mTau}^{-/-}$mice, indicating that postsynaptic deficits, aberrant network hyperactivity, and memory deficits are mechanistically linked. Our results directly implicate tau as a mediator of specific human mutant A53T $\alpha \mathrm{S}$-mediated abnormalities related to deficits in hippocampal neurotransmission and suggest a mechanism for memory impairment that occurs as a consequence of synaptic dysfunction rather than synaptic or neuronal loss. We hypothesize that these initial synaptic deficits contribute to network hyperexcitability which, in turn, exacerbate cognitive dysfunction. Our results indicate that these synaptic changes present potential therapeutic targets for amelioration of memory deficits in $\alpha$-synucleinopathies.
\end{abstract}

Keywords $\alpha$-Synuclein $\cdot$ Tau $\cdot$ Parkinson's disease $\cdot$ Lewy body disease $\cdot$ Dementia $\cdot$ Neuronal plasticity

\section{Introduction}

Parkinson's disease dementia (PDD) and Dementia with Lewy bodies (DLB) are closely related diseases in the $\alpha$-synucleinopathy family that comprise the second most common neurodegenerative dementia [53]. These and

Electronic supplementary material The online version of this article (https://doi.org/10.1007/s00401-019-02032-w) contains supplementary material, which is available to authorized users.

Michael K. Lee

mklee@umn.edu

Extended author information available on the last page of the article other $\alpha$-synucleinopathies are characterized by the presence of cytoplasmic inclusions termed Lewy bodies (LB) and Lewy neurites (LN), composed primarily of fibrillar $\alpha$-synuclein $(\alpha S)$ [105]. In addition to motor dysfunction arising from the loss of dopaminergic neurons in the substantia nigra pars compacta [82], the broad distribution of $\mathrm{LB} / \mathrm{LN}$ across multiple neuronal populations has led to an understanding in PD that the disease extends beyond the basal ganglia [1, 2]. Dementia in the $\alpha$-synucleinopathies is hypothesized to be a product of $\alpha \mathrm{S}$ abnormalities at cortical and hippocampal synapses. This pathogenic role for $\alpha \mathrm{S}$ is supported by genetic and pathological observations: mutations in the SNCA gene encoding $\alpha \mathrm{S}$ are causative for 
early onset, familial autosomal dominant forms of PD [48, 92, 93], and LBs and LNs are found in both familial and sporadic cases of PD [104]. While degeneration of cortical and hippocampal neurons is not a significant feature of PDD and DLB [42], cortical and hippocampal $\alpha$ S pathology show significant correlation with dementia $[4,24,42$, $43,53,105]$. Because $\alpha \mathrm{S}$ is a cytosolic protein enriched at presynaptic terminals with established roles as an inhibitor of neurotransmitter release $[3,81]$ and a presynaptic chaperone $[14-16,18]$, it is hypothesized that disease-associated $\alpha \mathrm{S}$ may cause memory deficits through mechanisms involving presynaptic dysfunction. We recently showed that mutant A53T human $\alpha \mathrm{S}\left(\mathrm{h} \alpha \mathrm{S}^{\mathrm{A} 53 \mathrm{~T}}\right)$ expression causes deficits in learning, memory, and synaptic plasticity in mice [110]. Significantly, while we show that presynaptic deficits, characterized by decreased probability of neurotransmitter release, are present in both wild-type and mutant human $\alpha \mathrm{S}$ expressing neurons, only h $\alpha \mathrm{S}^{\mathrm{A53T}}$ expression caused defects in postsynaptic function and synaptic plasticity. Mechanistically, this unique $h \alpha S^{\mathrm{A} 53 \mathrm{~T}}$ induced postsynaptic dysfunction is mediated through a process involving tau: GSK3 $\beta$-dependent tau phosphorylation, subsequent tau missorting to dendritic spines, and calcineurin-dependent AMPA receptor (AMPAR) internalization. These deficits in neurotransmission appear in the absence of overt neuropathology, suggesting that neuronal dysfunction is not a consequence of neurotoxicity and neurodegeneration.

In this study, we sought to extend our prior findings by mechanistically connecting our in vitro studies with the memory deficits in vivo. To accomplish this, we directly tested whether tau expression was required for $\alpha \mathrm{S}$-induced cellular, physiological, and behavioral deficits in the TgA53T mouse model of $\alpha$-synucleinopathy. We show that TgA53T mice exhibit progressive memory deficits associated with the presence of postsynaptic, but not presynaptic, deficits. More important, we demonstrate that loss of tau completely reversed the onset of memory deficits in multiple experimental paradigms and that tau is required for $\alpha \mathrm{S}$-mediated neurophysiological deficits, including postsynaptic dysfunction, impairments in glutamatergic neurotransmission, and short- and long-term plasticity. Significantly, these parameters are independent of any $\alpha S$ pathology or neurodegenerative changes. Finally, the onset of neurophysiological and memory deficits coincides with the onset of seizure-like network hyperactivity. We propose that early tau-dependent postsynaptic deficits caused by mutant $\alpha \mathrm{S}$ are mechanistically linked to the onset of network abnormalities and memory deficits. Our results provide novel insights on how pathological $\alpha S$ precipitates impairments in neurotransmission and memory loss and may inform the development of new therapeutic approaches for PDD and DLB.

\section{Materials and methods}

All animal studies were performed in accordance with the NIH guidelines for the use of animals in research and approved by the Institutional Animal Care and Use Committee at the University of Minnesota. Experimental group sizes $(n)$ are reported in each figure.

\section{Transgenic A53T a-synuclein mutant and tau-knockout mice}

We bred four key genotypes for this study. TgA53T animals contain a transgene expressing the human mutant A53T $\alpha$-synuclein $\left(\alpha \mathrm{S}, \mathrm{h} \alpha \mathrm{S}^{\mathrm{A} 53 \mathrm{~T}}\right.$ : line G2-3). All mice were maintained in the $\mathrm{C} 57 \mathrm{BL} / 6 \mathrm{~J}$ background strain (stock 0006644, Jackson Labs; Bar Harbor, ME, USA). TgA30P animals express human mutant $\mathrm{A} 30 \mathrm{P} \alpha \mathrm{S}\left(\mathrm{h} \alpha \mathrm{S}^{\mathrm{A} 30 \mathrm{P}}\right.$ : line $\mathrm{O} 2, \operatorname{Tg} \mathrm{A} 30 \mathrm{P}$ ) at similar levels to $\mathrm{TgA}$ 53 T, and $\mathrm{TgWT}$ animals express human wild-type $\alpha \mathrm{S}$ (h $\alpha \mathrm{S}^{\mathrm{WT}}$ : line I2-2, $\mathrm{TgWT}$ ), but at levels lower to $\mathrm{TgA} 53 \mathrm{~T}$ and $\mathrm{TgA} 30 \mathrm{P}$. Transgene expression for all animals is controlled by the mouse prion promoter (MoPrP) [65]. TgA53T, TgA53T/ $\mathrm{mTau}^{-1-}, \mathrm{TgA} 30 \mathrm{P}$, and TgWT were all heterozygous for their respective $h \alpha \mathrm{S}$ transgene. Non-transgenic (nTg) controls came from within these litters. To generate transgenic animals expressing $\mathrm{h} \alpha \mathrm{S}^{\mathrm{A} 53 \mathrm{~T}}$ (TgA53T) and lacking endogenous mouse tau $\left(\mathrm{mTau}^{-/-}\right)$, TgA53T males

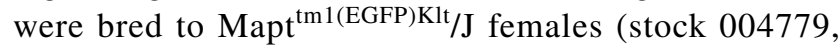
Jackson Labs) [113] in successive generations to generate offspring that lacked endogenous mouse tau expression and with, or without, $h \alpha \mathrm{S}^{\mathrm{A} 53 \mathrm{~T}}$ transgene expression. Transgenic progenies were identified by PCR analysis of tail DNA as previously described [65]. Because all mice were maintained on the C57BL/6J background, we were able to generate $\mathrm{TgA} 53 \mathrm{~T}$ and $\mathrm{nTg}$ cohorts separate from the TgA53T/mTau ${ }^{-/-}$and $\mathrm{mTau}^{-1-}$ cohorts. This approach was used, because the use of heterozygous mice for breeding leads to a very low yield of animals with the experimentally desired genotype (25\%), increased heterogeneity between littermates, and more importantly, a larger spread in birthdates and consequently ages of mice, introducing potential methodological variations. In addition, this low yield of experimentally desired mice would translate into a large population of unused, "wasted", animals, something we consciously worked towards avoiding. Generating $\mathrm{TgA} 53 \mathrm{~T} / \mathrm{mTau}^{+/+}(\mathrm{TgA} 53 \mathrm{~T})$ and TgA53T/mTau ${ }^{-/-}$cohorts via independent homozygous matings produced progeny within a tighter age range and allowed us to use $100 \%$ of the offspring for experiments.

The TgA53T (G2-3) mouse model exhibits an adultonset hyperactive locomotor phenotype [116] prior to 
the onset of motor dysfunction. This motor dysfunction phenotype rapidly progresses from slight ataxic signs (gait and balance abnormalities) to complete paralysis within 2-3 weeks [65]. This pattern of motor deficit is also observed in another transgenic mouse model expressing $h \alpha \mathrm{S}^{\mathrm{A} 53 \mathrm{~T}}$ under control of the MoPrP promoter (M83) as rotarod performance declines only following sudden and dramatic disease onset [35]. Since the initial characterization of $\mathrm{TgA}$ A3 $\mathrm{T}$ mice, the average age of disease onset has drifted from approximately 10 months of age to approximately 14 months of age (Lab of Michael K. Lee, unpublished data). Neuropathologically, the onset of motor symptoms in MoPrP-h $\alpha \mathrm{S}^{\mathrm{A} 53 \mathrm{~T}}$ transgenic mice (G2-3 and M83) is associated with the presence of $\alpha \mathrm{S}$ pathology in subcortical areas (midbrain, brain stem, and spinal cord) but not in forebrain regions including the hippocampus and amygdala [35, 65]. Any animals showing overt motor symptoms were excluded from further analysis.

Male mice were exclusively used for all behavior studies. For the electrophysiological, biochemical, and immunohistochemical analyses, both males and females were used. In these studies, efforts were made to use equal numbers of mice from each sex within each genotype cohort.

All mice in the colony were kept under specific pathogenfree (SPF) conditions in a $14 \mathrm{~h}(\mathrm{~h})$ light/10 h dark cycle, and had free access to food and water. All housing and experimental protocols involving mice were conducted with strict adherence to the National Institutes of Health (NIH) Animal Care and Guidelines and were reviewed and approved by the Institutional Animal Care and Use Committee (IACUC) at the University of Minnesota.

\section{Dissociated neuronal culture electrophysiology}

Dissociated neuronal cultures were established from harvested from mouse hippocampi postnatal day 0 or 1 (P0-P1) as previously described [110] with modifications. Briefly, mouse hippocampi were dissected out and stored individually by pup in Hibernate A media (Brain Bits; Springfield, IL, USA) at $4{ }^{\circ} \mathrm{C}$. While stored, each pup from the cultured litter was genotyped. Cerebellar tissue was used for genomic DNA isolation via QuickExtract DNA (Epicentre-Lucigen; Madison, WI, USA) and genotyping of pups was performed immediately after hippocampal isolation. Following genotype identification, hippocampi of identical genotypes were pooled, dissociated, and plated on onto $35 \mathrm{~mm} \mu$-dishes containing a poly-D-lysine and laminin-coated polymer coverslip (Ibidi; Fitchburg, WI, USA). $24 \mathrm{~h}$ after initial plating, media were removed and NbActiv4 growth media were added (Brain Bits). NbActiv4 media were refreshed every 3-4 days by removing $1 \mathrm{~mL}$ media in the dishes and adding $1 \mathrm{~mL}$ fresh media. For all procedures and media exchanges, solutions were equilibrated in a tissue culture incubator $\left(37{ }^{\circ} \mathrm{C}, 5 \% \mathrm{CO}_{2}\right)$ for at least $2 \mathrm{~h}$ prior to use. The age of in vitro dissociated cultured hippocampal neurons began with the day of initial plating, and each day that followed was counted as 1 day in vitro (DIV). All experiments were performed on neurons from at least three independent cultures with a minimum of five animals per culture. Miniature excitatory postsynaptic currents (mEPSC) were recorded from cultured dissociated mouse hippocampal neurons at 21-25 DIV with a glass pipette (resistance of $\sim 5 \mathrm{M} \Omega$ ) as previously described [110]. Recordings ranged from 3 to $15 \mathrm{~min}$ and stable traces longer than $1 \mathrm{~min}$ in duration were analyzed. All mEPSCs $>2 \mathrm{pA}$ were manually counted with MiniAnalysis (Synaptosoft Inc; Fort Lee, NJ, USA). Each mEPSC event was visually inspected and only events with a distinctly fast-rising phase and a slow-decaying phase were accepted. Relative cumulative frequencies were derived from individual events and the averaged parameters from each neuron were treated as single samples in any further statistical analyses.

\section{Acute hippocampal slice electrophysiology}

Acute coronal hippocampal slices (approximately 350 $\mu \mathrm{m}$ thick) were obtained from two age windows of mice (2-3 months and 5-6 months) from $\mathrm{nTg}, \mathrm{TgA} 53 \mathrm{~T}, \mathrm{TgA53T} /$ $\mathrm{mTau}^{-/-}$, and $\mathrm{mTau}^{-/-}$animals utilizing well-established methods [110].

Briefly, slices were incubated in ACSF (containing in $\mathrm{mM}: \mathrm{NaCl} 124, \mathrm{KCl} 5, \mathrm{NaH}_{2} \mathrm{PO}_{4} 1.25, \mathrm{MgSO}_{4} 2, \mathrm{NaHCO}_{3}$ $26, \mathrm{CaCl}_{2}$ 2, glucose 10; gassed with $95 \% \mathrm{O}_{2}, 5 \% \mathrm{CO}_{2}$, and maintained between $\mathrm{pH} 7.3$ and 7.4) at room temperature for at least $1 \mathrm{~h}$ before use. For studies, slices were transferred to an immersion-recording chamber, superfused at $2 \mathrm{~mL} /$ min with oxygenated ACSF, and visualized under an Olympus BX50WI microscope (Olympus Optical; Japan). To study excitatory postsynaptic currents (EPSCs), picrotoxin $(50 \mu \mathrm{M})$ and CGP54626 $(1 \mu \mathrm{M})$ were added to the solution to block GABA-A and GABA-B receptors, respectively. Whole-cell electrophysiological recordings were obtained from hippocampal CA1 pyramidal neurons using patch electrodes (3-10 M $\Omega$ ) filled with an internal solution containing in mM: cesium gluconate 117, HEPES 20, EGTA 0.4, $\mathrm{NaCl} 2.8$, TEA-Cl 5, ATP 2, GTP 0.3, and kept at pH 7.3. Recordings were obtained with PC-ONE amplifiers (Dagan Instruments; Minneapolis, MN, USA). Membrane potentials were held at $-70 \mathrm{mV}$. Signals were filtered at $1 \mathrm{kHz}$, acquired at a $10 \mathrm{kHz}$ sampling rate, and fed to a Digidata 1440A digitizer (Molecular Devices; San Jose, CA, USA). pCLAMP 10.4 (Axon Instruments, Molecular Devices; San Jose, CA, USA) was used for stimulus generation, data display, data acquisition, and data storage. To record evoked EPSCs, theta capillaries filled with ACSF were used for bipolar stimulation and placed in the stratum radiatum to 
stimulate Schaffer collaterals. Input-output curves of EPSCs were made by increasing stimulus intensities from 0 to 100 $\mu \mathrm{A}$. Paired-pulse facilitation was done by applying paired pulses [2 ms (ms) duration] with 25, 50, 75, 100, 200, 300, and $500 \mathrm{~ms}$ inter-pulse intervals. The paired-pulse ratio was calculated by dividing the amplitude of the second EPSC by the first (PPR =EPSC-2/EPSC-1). Synaptic fatigue was assessed by applying 15 consecutive stimuli in $25 \mathrm{~ms}$ intervals. AMPA currents were obtained at a holding potential of $-70 \mathrm{mV}$. NMDA currents were obtained at a holding potential of $+30 \mathrm{mV}$. To ascertain the AMPA-to-NMDA receptor current ratio, the NMDA component was measured $50 \mathrm{~ms}$ after the stimulus when the AMPA component had decayed. Recordings of miniature EPSCs (mEPSCs; $V_{\mathrm{h}}=-70 \mathrm{mV}$ ) were made in the presence of tetrodotoxin (TTX; $1 \mu \mathrm{M}$ ) in addition to the respective solution. For long-term potentiation (LTP), CA1 pyramidal neurons first underwent a baseline recording of $10 \mathrm{~min}$ followed by tetanic stimulation in the Schaffer collaterals (4 trains at $100 \mathrm{~Hz}$ for $1 \mathrm{~s} ; 30 \mathrm{~s}$ intervals). After LTP induction, neurons were recorded for $50 \mathrm{~min}$. The presence of LTP was determined by comparing the average EPSC amplitudes from last $5 \mathrm{~min}$ of pre-stimulus baseline recording to the average EPSC amplitudes from the last 5 min post-stimulus recordings. All experiments were performed at room temperature.

\section{Behavioral testing}

Behavioral testing was performed with the support and guidance of the Mouse Behavior Core at the University of Minnesota. ANY-maze software (Stoelting Co.; Wood Dale, IL, USA) was used in conjunction with paired video cameras to track and record animal movements during all behavioral testing and all subsequent analyses. Behavior experiments, unless dictated by testing protocols, were not performed on consecutive days, giving animals at least 2 days to rest between experiments. Mice were also habituated to handling prior to testing. Animals from all genotypes were tested together. Each behavioral age point came from a separate cohort. In addition, all groups tested, including those at different age points, went through the battery of tests in the same order.

\section{Open field}

Locomotor activity was assessed using open-field testing. Animals were placed individually into a square $40 \mathrm{~cm} \times 40 \mathrm{~cm}$ arena with white, opaque walls and flooring, lit to 200 1x. Movement was videorecorded for $60 \mathrm{~min}$ and began immediately after placing the animal in the open-field testing chamber. After the test, animals were returned to their home cage.

\section{Barnes maze}

Spatial learning and memory were assessed via Barnes maze (San Diego Instruments; San Diego, CA, USA), following established protocols [8, 108]. The maze itself consists of a white plastic circular top with 20, evenly sized and evenly spaced holes around the perimeter. Spatial cues were placed on all four walls of the behavioral testing room, lit to $300 \mathrm{~lx}$ during testing. Mice were acclimatized to the testing room for $30 \mathrm{~min}$ at the beginning of each training session. Training days consisted of 4 trials per day for 4 days. Training trials ended with the subject climbed into the escape box within the goal quadrant located under 1 of the holes or when the maximum trial duration of $180 \mathrm{~s}$ was reached. Upon entering the escape box during training, room lights turned off and animals remained in the escape box for $60 \mathrm{~s}$ before returning to their home cage in the testing room to await the next trial. While the platform was rotated between each trial on each day (to obscure the impact any animal scents or non-spatial cues on the maze), the location of the escape box and goal quadrant relative to the room remained constant during all training trials and days. Subjects were run in small groups of six mice or less, so that no more than 20 min passed between trials for a given animal during training. On the day following the last training trial, memory was assessed in single $90 \mathrm{~s}$ probe trial tests, where the target escape box in the goal quadrant was replaced with a false box cover identical to the other 19 holes, and the exploration pattern of each subject was examined.

\section{Y maze}

Short-term spatial learning and memory was assessed via Y maze. Animals underwent 30 min acclimation periods in the testing room prior to testing. Cues were visible on walls of the testing room as well as within the maze, at the end of each arm (extra-maze and intra-maze, respectively). The Y maze was constructed out of opaque white plastic and located at the center of the testing room lit to $150 \mathrm{~lx}$. During the first of two phases, only two of the three arms were available for exploring during the 10 min learning trial: the start arm and the familiar arm. For all trials, animals were placed at the end of the start arm, furthest point from center. During the 60 min inter-trial interval between learning and recognition, animals returned to their home cage, but remained in testing room. The 5 min recognition trial was then performed, with all three arms were available for exploration: start, familiar, and novel. The Y 
maze was also cleaned between each trial/animal to avoid confounds due to scent.

\section{Context fear conditioning}

Context fear conditioning was conducted using the NearInfrared (NIR) Video Fear Conditioning package for mice (Med Associates, Inc; Fairfax, VT, USA). A context conditioning environment (specific olfactory, tactile, and visual elements) is paired with foot shocks on the first day: a 10 min context conditioning trial was first performed in the NIR fear conditioning chamber: electrified metal bars on the floor, providing $0.7 \mathrm{~V}$ foot shocks for $2 \mathrm{~s} 5$ times per trial at variable intervals averaging $90 \mathrm{~s}$ between shocks, squared off corners and metal walls, and a 33\% Simple Green solution for scent. $24 \mathrm{~h}$ following conditioning animals were underwent the context memory trial, where freezing was assessed for $3 \mathrm{~min}$ with identical chamber conditions to the conditioning trial except no foot shocks (similar). If the animal successfully learns the context-shock association, reexposure to the context environment $24 \mathrm{~h}$ post-conditioning, the "similar" setting, will elicit fear in the animal placed in that environment. $2 \mathrm{~h}$ after the similar trial, mice were placed in the chamber for the novel context trial (Novel), white, solid plastic flooring and curved walls with a stripe design inside, and a $0.5 \%$ vanilla solution for scent, to show the context specificity of the fear memory.

\section{Western blot analyses}

\section{Chemiluminescence western blotting}

At predefined age points, mice were harvested and brain regions (cortices and hippocampi, in particular) were dissected out and stored at $-80{ }^{\circ} \mathrm{C}$. To extract proteins, cortical and hippocampal samples from $-80{ }^{\circ} \mathrm{C}$ were first thawed at $-20{ }^{\circ} \mathrm{C}$ overnight before being weighed and homogenized via Dounce homogenization in 10 volumes of TNE solution in $\mathrm{mM}$ : Tris- $\mathrm{HCl} 50, \mathrm{NaCl} 150$, and EDTA 5. Following homogenization, an equal volume of Complete TNE was added: TNE plus $0.5 \%$ NP40, $0.5 \%$ DOC, $1 \%$ SDS, and HALT protease and phosphatase inhibitors (Thermo Fisher Scientific; Waltham, MA, USA). Samples were then spun down at $16,000 \mathrm{~g}$ for $90 \mathrm{~min}$ at $4{ }^{\circ} \mathrm{C}$. Supernatant was collected and subjected to immunodepletion via serial incubations with Protein A and G Mag Sepharose beads (GE Life Science; Pittsburgh, PA, USA) rocking at $4{ }^{\circ} \mathrm{C}$ for $60 \mathrm{~min}$. Protein concentration was assessed via BCA assay (Pierce, Thermo; Rockford, IL, USA). Samples were prepared to equal concentration in reducing, SDS sample, Laemmli buffer (Boston BioProducts; Ashland, MA, USA). For western blot analysis, protein lysates were run on Criterion ${ }^{\mathrm{TM}} \mathrm{TGX}^{\mathrm{TM}}$ gels
(Bio-Rad; Hercules, CA, USA) and transferred onto nitrocellulose membranes. Membranes were then blocked using 5\% non-fat dry milk in tris-buffered saline (TBS) with $0.1 \%$ Tween 20 (TBSTw) for $1 \mathrm{~h}$ at room temperature (RT). Primary antibodies were diluted in OneBlock solution (Genesee Scientific; San Diego, CA, USA) and incubated on membranes overnight at $4{ }^{\circ} \mathrm{C}$. Horseradish peroxidase (HRP)-conjugated secondary antibodies (Invitrogen; Carlsbad, CA, USA) were diluted in 5\% non-fat dry milk in TBSTw and incubated on membranes $1 \mathrm{~h}$ at RT. Membranes were then developed using chemiluminescent substrates (Bio-Rad and Thermo) and the ImageQuant LAS 4000 detection system (GE Life Sciences). Densitometry on western blot images was subsequently analyzed using the ImageQuant TL 8.1 software (GE Life Sciences).

\section{Fluorescence western blotting}

SDS-PAGE was performed on precast $10.5-14 \%$ Criterion $^{\mathrm{TM}}$ Tris-Tricine gels, $10.5-14 \%$ or $4-10.5 \%$ Tris- $\mathrm{HCl}$ gels (Bio-Rad). Protein levels were normalized using $10-100 \mu \mathrm{g}$ of protein per sample (depending on the targeted protein). The samples were resuspended with $4 \times$ Tricine loading buffer and boiled for $5 \mathrm{~min}$ before loading. Proteins were transferred onto $0.2-\mu \mathrm{m}$ nitrocellulose membrane (Bio-Rad) following electrophoresis. Membranes were blocked in 5\% BSA (Sigma; St. Louis, MO, USA) in TBSTw for 1-2 $\mathrm{h}$ at room temperature and probed with the appropriate antisera/antibodies diluted in 5\% BSA in TBSTw. Primary antibodies were probed with secondary antibodies conjugated with infrared dyes (LI-COR Biosciences; Lincoln, NE, USA). Densitometry analyses were performed using the Odyssey software (LICOR Biosciences). Normalization was performed against GAPDH. Quantification by software analysis was performed as described previously [5, 56, 59-61, 103].

\section{Dot blot analyses}

Protein isolates were obtained from samples at the same time that they were being prepared for western blotting. Samples diluted to identical concentrations $(1 \mu \mathrm{g} / \mu \mathrm{L})$ and $2 \mu \mathrm{g}$ of sample were adsorbed onto a nitrocellulose membrane and air-dried for $30 \mathrm{~min}$. Following activation in $10 \%$ methanol (in TBS), membranes were blocked in TBS containing 5\% bovine serum albumin (BSA) for $30 \mathrm{~min}$ at room temperature (RT). Samples were then incubated in primary antibody overnight at $4{ }^{\circ} \mathrm{C}$ in $5 \%$ BSA in TBS. Following primary antibody incubation and TBS washes, secondary incubation was performed for $1 \mathrm{~h}$ at RT in the dark in 5\% BSA in TBS with IRDye secondary antibodies (anti-mouse IgG-IR800 
at 1:100,000 and anti-rabbit IgG-IR680 at 1:150,000) (LICOR Biosciences). Membranes were then washed, imaged, and analyzed using the LI-COR Odyssey-imaging system.

\section{Insoluble and soluble protein extraction}

An equal volume of $2 \%$ Triton $^{\mathrm{TM}} \mathrm{X}-100$ (Sigma-Aldrich; St. Louis, MO, USA) in TNE was added to the Dounce homogenized lysate in TNE, mixed, and then sonicated for $30 \mathrm{~s}$ at $4{ }^{\circ} \mathrm{C}$. Samples were then spun down at $20,000 \mathrm{~g}$ for $60 \mathrm{~min}$ at $4{ }^{\circ} \mathrm{C}$. The supernatant from this spin was saved as the soluble fraction. The pellet was saved as the insoluble fraction, washed in $1 \%$ Triton $^{\mathrm{TM}} \mathrm{X}-100$ in TNE and spun down again. Complete TNE was added to both soluble and insoluble fractions. Fractions were then sonicated, boiled for $10 \mathrm{~min}$ at $95^{\circ} \mathrm{C}$, and spun down at $16,000 \mathrm{~g}$ for $15 \mathrm{~min}$ at $4{ }^{\circ} \mathrm{C}$, and then, the supernatant from each fraction was saved. Protein concentration was assessed via BCA assay (Pierce, Thermo; Rockford, IL, USA). Samples were then prepared for western blotting identically to the "Chemiluminescent Western Blotting" protocol. After transfer, membranes were stained with $0.1 \%$ Ponceau S solution (Sigma-Aldrich) to confirm equal protein loading and transfer. Samples then underwent primary and secondary antibody incubation and chemiluminescent detection following "Chemiluminescent Western Blotting" methods.

\section{Immunohistochemical analyses}

At predefined age points, mice were anesthetized with isoflurane and euthanized via transcardial perfusion with saline. Animals were first perfused with ice cold K-free PBS, containing in $\mathrm{mM}: \mathrm{NaCl} 13, \mathrm{Na}_{2} \mathrm{HPO}_{4} \cdot 2 \mathrm{H}_{2} \mathrm{O} 0.7$, and $\mathrm{NaH}_{2} \mathrm{PO}_{4} \cdot 2 \mathrm{H}_{2} \mathrm{O} 0.3$, and adjusted to $\mathrm{pH}$ 7.2. Following saline perfusion, animals were then perfuse-fixed with $4 \%$ paraformaldehyde (PFA). Brains were then isolated and stored in $4 \%$ PFA at $4{ }^{\circ} \mathrm{C}$ for an additional $48 \mathrm{~h}$ before being transferred to a $30 \%$ sucrose solution in PBS prior to slicing. After a minimum of $72 \mathrm{~h}$ in sucrose solution, brains were sliced coronally at a thickness of $30 \mu \mathrm{M}$ via HM 450 sliding microtome (Thermo Fisher Scientific) and stored in a cryoprotectant solution (30\% sucrose and 30\% ethylene glycol in PBS) prior to immunostaining. Immunofluorescent staining was preformed utilizing the Pelco BioWave Plus (Ted Pella; Redding, CA, USA) and mounted on slides for imaging. Prior to staining sections were rinsed in TBS, permeabilized with $0.1 \%$ Triton X-100 in TBS and blocked in 50\% Background Sniper solution in TBS (Biocare Medical; Pacheco, CA, USA). Primary and secondary antibodies were diluted to target concentrations in 5\% Background Sniper (Biocare Medical) in TBSTw and allowed to incubate on sections in the Pelco BioWave for $1.5 \mathrm{~h}$ each. Alexa Fluor (Abcam; Cambridge, MA, USA) or Alexa Fluor Plus
(Thermo Fisher Scientific) secondary antibodies were used as dictated by primary antibody host. If required, sections were then 4',6-diamidino-2-phenylindole (DAPI)-counterstained. All sections were treated with TrueVIEWTM (Vector Laboratories; Burlingame, CA, USA) for autofluorescence quenching and mounted on slides for future imaging. Confocal microscopy images were acquired with the Nikon C2 Confocal Microscope System (Nikon; Melville, NY, USA). Imaging processing and analysis were performed using the NIS-Elements software (Nikon). Staining, imaging, and analysis were performed in collaboration with the University of Minnesota's University Imaging Centers on the Twin Cities campus. Analysis and quantification of biomarkers of neuronal network hyperexcitability [c-Fos, neuropeptide $\mathrm{Y}$ (NPY), and calbindin] were performed as described previous [89].

\section{Antibodies}

A detailed list of all antibodies used for experiments and studies here can be found in Suppl. Table 1 (Online Resources).

\section{Experimental design and statistical analyses}

All statistical analyses were performed in Prism 8.1.0 (GraphPad Software; San Diego, CA, USA). Data visualization and presentation were performed via Prism (GraphPad) and JMP 14 (SAS; Cary, NC, USA). For parametric data: one-, two-, and three-way ANOVAs were utilized for one, two, and three variable analyses on multiple groups, respectively; $t$ tests were also performed when analyzing only two groups. For nonparametric data, Kruskal-Wallis one-way ANOVA for three or more groups and Mann-Whitney test for two groups. Posthoc analyses were performed on all data that were significantly different. Welch's correction, Sidak's posthoc analysis, and Tukey's posthoc analyses were used due to considerations for within-group variances and sample size. The Geisser-Greenhouse correction was used for two- and three-way repeated measures ANOVAs due to considerations for sphericity. For all, statistical significance was set for $\alpha=0.05$. Data representations are described in figure legends.

\section{Results}

\section{Mutant a-synuclein-dependent cognitive dysfunction in spatial learning and memory is both progressive and tau-dependent}

Several $\alpha$-synuclein $(\alpha S)$ transgenic mouse models display memory deficits $[19,67,68,70]$, including the model 
expressing human mutant A53T $\alpha \mathrm{S}$ (TgA53T) [19, 67, $68,90,110]$. However, the mechanistic basis for cognitive impairment in these mouse models is poorly defined. Previously, we established a novel connection between human mutant $\mathrm{A} 53 \mathrm{~T} \alpha \mathrm{S}\left(\mathrm{h} \alpha \mathrm{S}^{\mathrm{A} 53 \mathrm{~T}}\right)$ and postsynaptic impairments in AMPAR function that require tau phosphorylation and mislocalization to dendritic spines [110]. Because these glutamatergic postsynaptic impairments are linked to cognitive dysfunction [47], we hypothesized that cognitive deficits in $\mathrm{TgA} 53 \mathrm{~T}$ mice are tau-dependent. To directly test the requirement of tau in mediating $\alpha \mathrm{S}$-induced memory loss, we generated $\mathrm{TgA} 53 \mathrm{~T}$ mice lacking endogenous mouse tau expression by breeding $\operatorname{Tg}$ A53T mice to the mouse tau-knockout mice $\left(\mathrm{mTau}^{-/-}\right)$[113]. The four genotypes (TgA53T, $\mathrm{TgA} 53 \mathrm{~T} / \mathrm{mTau}^{-/-}, \mathrm{mTau}^{-/-}$, and non-transgenic (nTg) littermate controls) appear to develop and age normally for the duration of the study.

Previously, we showed that $\operatorname{Tg} \mathrm{A} 53 \mathrm{~T}$ mice exhibit spatial memory deficits in the Barnes maze (BM) $[8,108]$ at 12 months of age [110]; however, it is unknown if general overexpression of $h \alpha \mathrm{S}$ also leads to memory deficits. To confirm that only $\mathrm{TgA}$ 53 $\mathrm{T}$ mice exhibit memory deficits in our experimental conditions, we examined whether TgWT $\left(h \alpha \mathrm{S}^{\mathrm{WT}}\right)$ and $\mathrm{TgA} 30 \mathrm{P}\left(\mathrm{h} \alpha \mathrm{S}^{\mathrm{A} 30 \mathrm{P}}\right)$ mice in our colony exhibit deficits in spatial learning and memory at older ages. $\mathrm{TgA53T}$ and $\mathrm{TgA} 30 \mathrm{P}$ mice have similar human mutant $\alpha \mathrm{S}$ transgene expression levels, while TgWT mice display lower human $\alpha \mathrm{S}$ transgene expression by comparison [110]. We previously showed that $\mathrm{TgWT}$ and $\mathrm{TgA} 30 \mathrm{P}$ neurons exhibit presynaptic deficits as indicated by reductions in the probability of neurotransmitter release, but intact postsynaptic function and long-term potentiation (LTP) [110]. Thus, we employed these models to directly test whether presynaptic deficits alone are sufficient to cause impairments in learning and memory. Spatial learning and memory analysis of 12-month-old TgWT, TgA30P, and nTg littermates using the $\mathrm{BM}$ paradigm shows that all groups of mice are able to learn and retain goal quadrant and escape box location (Suppl. Figure 1b-d, Online Resources). Taken together, our findings show that $\alpha \mathrm{S}$-dependent presynaptic impairments alone are not sufficient to cause memory deficits in mouse models of $\alpha$-synucleinopathy under our experimental conditions and that memory deficits in $\mathrm{TgA}$ A3 T mice involve both pre- and postsynaptic abnormalities.

To better define memory deficits in $\operatorname{TgA} 53 \mathrm{~T}$ mice, we assessed the progressive nature these deficits hippocampal-dependent spatial learning and memory via BM and whether endogenous tau was required for cognitive deficits in $\operatorname{TgA} 53 \mathrm{~T}$ mice. At 6 months of age, $\mathrm{TgA} 53 \mathrm{~T}$ mice exhibit a slight delay in acquisition compared to the $\mathrm{nTg}$ land $\mathrm{mTau}^{-1-}$ controls (Fig. 1a), mitigated by extra training, as they successfully learn the location of the escape hole in the goal quadrant in a timing similar to controls by training day 4 (Fig. 1a). Consistent with the previous data, 12-month-old TgA53T mice display severe impairments in the ability to learn the BM task, as they failed to display improved performance over consecutive training days (Fig. 1b). Significantly, the loss of tau completely reverses the $h \alpha \mathrm{S}^{\mathrm{A} 53 \mathrm{~T}}$-mediated learning deficit exhibited by $\mathrm{Tg}$ A53T mice, as $\mathrm{TgA} 53 \mathrm{~T} / \mathrm{mTau}^{-/-}$showed normal learning during training in the acquisition phase.

In the ensuing probe trial, a putative measure for spatial learning and memory retention, all 6-month-old animals, including $\mathrm{TgA53T}$, spent significantly more time in the goal quadrant compared to other quadrants in the maze (Fig. 1d, e; Suppl. Figure 2a, f, Online Resources), indicating that TgA53T mice have normal long-term spatial memory at 6 months of age. By 12 months, TgA53T mice did not show evidence of spatial memory retention during the probe trial, consistent with impaired memory acquisition (Fig. 1d, e; Suppl. Figure 2b, f, Online Resources). The memory deficits in the 12-month-old TgA53T mice is independent of motor deficits, as the total distance traveled during the probe test was comparable between groups at both 6 and 12 months of age (Suppl. Figure 2c, d, Online Resources).

Consistent with the normal learning and acquisition exhibited by $\mathrm{TgA} 53 \mathrm{~T} / \mathrm{mTau}^{-1-}$ mice, loss of tau expression completely rescues $\mathrm{TgA}$ A3T-associated memory deficits as 12-month-old TgA53T/mTau ${ }^{-1-}$ effectively learn and recall escape hole location within the goal quadrant. Collectively, these results demonstrate that tau expression is required for the progressive spatial learning and memory deficits in the TgA53T model.

\section{TgA53T mice exhibit deficits in multiple memory modalities}

While $\operatorname{Tg} \mathrm{A} 53 \mathrm{~T}$ mice demonstrate intact spatial learning and memory relative to nTg littermates at 6 months of age, hippocampal LTP deficits occur by 6 months in this model [110]. Given that $\operatorname{Tg}$ A53T mice may display mild BM learning deficits in early training days at 6 months of age, we hypothesized that $\mathrm{TgA53T}$ mice may exhibit more obvious tau-dependent deficits at earlier ages in other memory modalities involving hippocampal function. We first used contextual fear conditioning (CFC) to determine if TgA53T mice show deficits in this dual hippocampal and amygdaladependent task [7, 76, 91]. 3-month-old TgA53T mice show normal learning and memory comparable to the $\mathrm{nTg}$ littermates (Fig. 2a-c). At 6 months of age, TgA53T mice respond similarly to foot shocks during the context conditioning trial as compared to $\mathrm{nTg}, \mathrm{TgA} 53 \mathrm{~T} / \mathrm{mTau}^{-/-}$, and $\mathrm{mTau}^{-/-}$cohort counterparts (Fig. $2 \mathrm{~d}$ ), indicating that these mice do not exhibit gross sensorimotor abnormalities that could confound these findings. TgA53T mice exhibit significantly less freezing when exposed to the "similar" context 

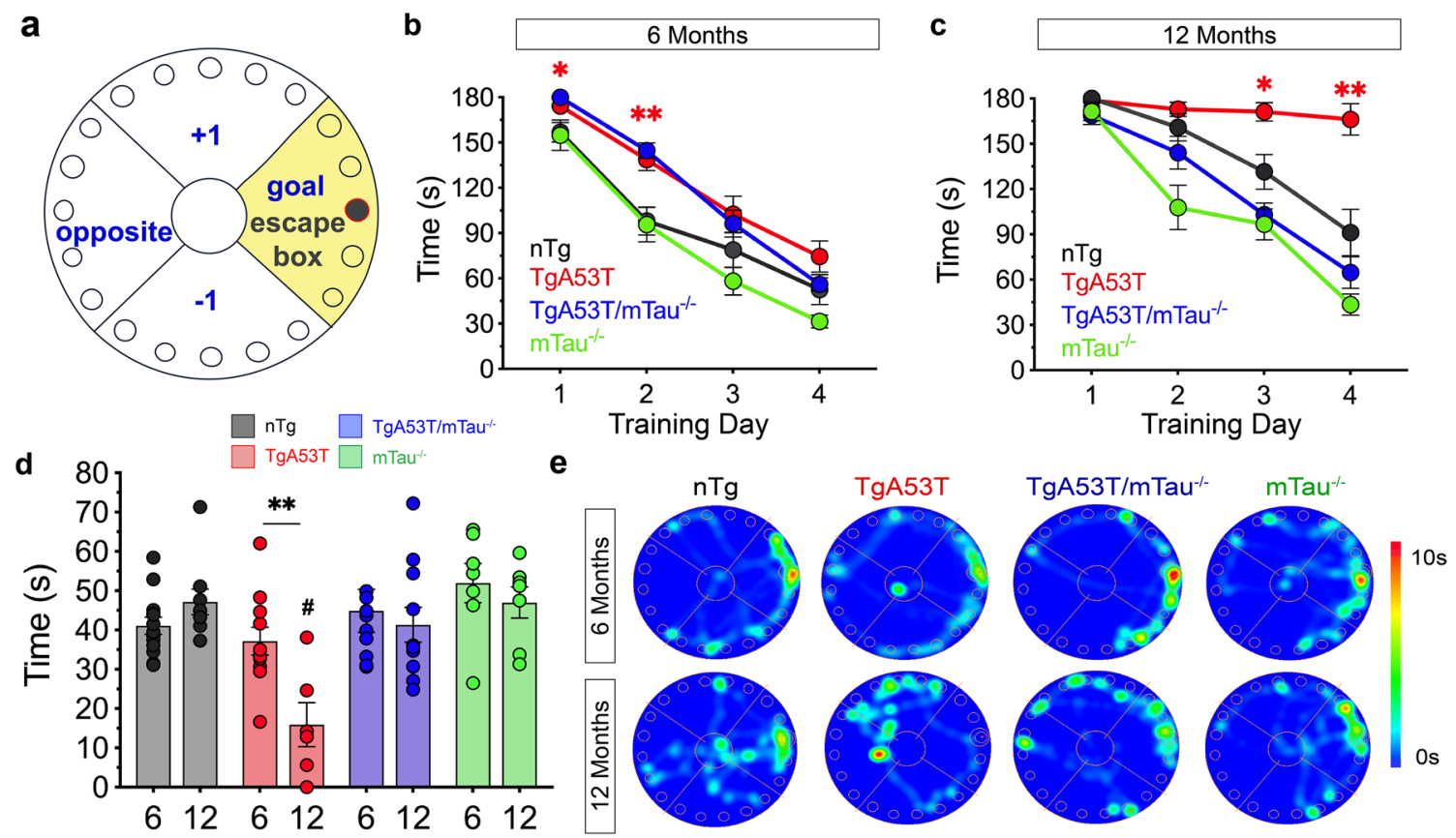

Fig. 1 Mutant A53T $\alpha$ S-driven deficits in spatial learning and memory are progressive and tau-dependent. Average duration of training trials per group for each of the 4 training days during the Barnes Maze (BM) when tested at either 6 (a) or 12 months of age $(6 \mathrm{M}$ or $12 \mathrm{M}$ ) (b). $6 \mathrm{M}$ training: three-way repeated measures ANOVA with Geisser-Greenhouse correction and Tukey's posthoc analysis revealed a significant effect of training day $\left[F_{(2.448,105.3)}\right)=190.7$, $p<0.0001]$, significant effect of $\alpha \alpha \mathrm{S}^{\mathrm{A53T}}$ genotype $\left[F_{(1,43)}=18.63\right.$, $p<0.0001]$, no significant effect of $\mathrm{mTau}^{-/-}$genotype $\left[F_{(1.43}\right)=190.7$, $p=0.2926]$, and no significant training day*h $\alpha \mathrm{S}^{\mathrm{A} 53 \mathrm{~T} *} \mathrm{mTau}^{-/-}$ interaction $\left[F_{(3,129)}=0.1160 p=0.9506\right]$. $12 \mathrm{M}$ training: three-way repeated measures ANOVA with Geisser-Greenhouse correction and Tukey's posthoc analysis revealed a significant effects of training day $\left[F_{(2.192,63.56)}=62.15, p<0.0001\right], h \alpha \mathrm{S}^{\mathrm{A} 53 \mathrm{~T}}$ genotype $\left[F_{(1,29)}=13.78\right.$, $p=0.0009]$, and $\mathrm{mTau}^{-/}$genotype $\left[F_{(1,29)}=49.05, p<0.0001\right]$, and no significant training day*ho $\alpha \mathrm{S}^{\mathrm{A} 53 \mathrm{~T}} * \mathrm{mTau}^{-1-}$ interaction $\left[F_{(3,87)}=3.734, p=0.0141\right]$. c BM diagram for testing and probe

as compared to the other three strains tested (Fig. 2e), indicating that CFC is impaired in 6-month-old TgA53T mice. All groups displayed reduced freezing tendencies in the "novel" setting, controlling for any sensorimotor differences (Fig. 2c, f). Significantly, TgA53T/mTau ${ }^{-1-}$ animals showed equivalent CFC capacities compared to control mice (nTg and $\mathrm{mTau}^{-/-}$), demonstrating that tau is required for mutant $\alpha \mathrm{S}$-dependent deficits in CFC.

Both the BM and CFC represent situations that subject mice to stressful environments to promote task performance. Thus, to reduce any confounds associated with the differential stress responses, we asked whether $\operatorname{TgA} 53 \mathrm{~T}$ mice have cognitive deficits in short-term memory using a spatial variant of the Y maze (YM), a less stressful assessment of spatial learning and memory [25]. Animals undergo an initial learning trial, where the "novel" arm is blocked off followed by a "recognition" trial, where all arms are open trial, with yellow shading indicating goal quadrant and dark grey showing escape box location in that quadrant. d Time spent in goal quadrant during probe trial for $6 \mathrm{M}$ or $12 \mathrm{M}$ mice. To compare within genotype between 6 and 12M: unpaired $t$ test with Welch's correction; TgA53T: $t=3.369$ and $d f=15(* * p=0.0042)$. To compare between genotypes at $6 \mathrm{M}$ or $12 \mathrm{M}$ : one-way ANOVA with Tukey's posthoc analysis. $12 \mathrm{M}$ group probe test: $F_{(3,29)}=9.216\left({ }^{\#} p=0.0002\right)$. $6 \mathrm{M}: \quad n_{\mathrm{nTg}}=13 ; \quad n_{\mathrm{TgA} 53 \mathrm{~T}}=11 ; \quad n_{\mathrm{TgA} 53 \mathrm{~T} / \mathrm{mTau}}^{-/-}=10 ; \quad n_{\mathrm{mTau}}^{-/-}=8 . \quad 12 \mathrm{M}:$ $n_{\mathrm{nTg}}=9 ; n_{\mathrm{TgA} 53 \mathrm{~T}}=7 ; n_{\mathrm{TgA} 53 \mathrm{~T} / \mathrm{mTau}}^{-l-}=11 ; n_{\mathrm{mTau}}^{-l-}=8$. e Probe test BM occupancy heat maps during probe test obtained by averaging the location of all animals in each genotype and cohort. Orientation of BM is shown in c. In all figures: (1) the color code is: nTg (black), TgA53T (red), TgA53T/mTau ${ }^{-/-}$(blue), and $\mathrm{mTau}^{-/-}$(green); (2) the data are expressed as mean \pm standard error of the mean (SEM); and (3) $* p<0.05, * * p<0.01, * * * p<0.001$, and $* * * * p<0.0001$, unless stated otherwise

for exploration (Suppl. Figure 3a, Online Resources). The recognition trial takes advantage of an animal's propensity to explore novel objects and environments and tests their capacity to discriminate between novel and familiar environments $[6,109]$. As such, measuring the amount of time spent in the novel $(\mathrm{N})$ versus familiar $(\mathrm{F})$ arms of the YM provides an assessment of short-term spatial learning and memory. 6-month-old nTg mice spent significantly more time in the $\mathrm{N}$ arm, while littermateTgA53T mice spent equal amounts (chance) between $\mathrm{N}$ and $\mathrm{F}$ arms during the recognition trial (Suppl. Figure 3b, c, Online Resources). The h $\alpha \mathrm{S}^{\mathrm{A} 53 \mathrm{~T}}$ mediated reductions in spatial discrimination are suggestive of an impaired capacity for this hippocampal-dependent short-term spatial memory at 6 months of age. More importantly, the YM spatial discrimination deficit was reversed in $\mathrm{TgA} 53 \mathrm{~T} / \mathrm{mTau}^{-1-}$ mice, indicating that endogenous tau expression is required for $h \alpha \mathrm{S}^{\mathrm{A} 53 \mathrm{~T}}$-associated impairments 

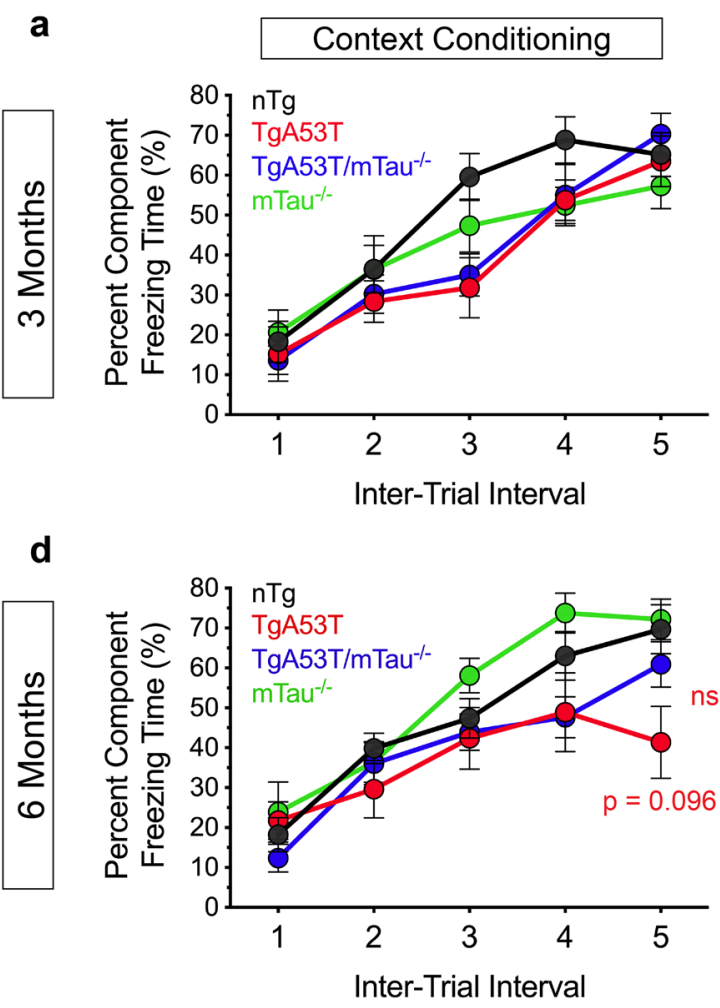

Fig. 2 Mutant synuclein impairs hippocampal contributions to contextual fear conditioning in both age and tau-dependent manners. Contextual fear conditioning (CFC) in mice at 3 months (3M) (a-c) and 6 months $(6 \mathrm{M})$ of age $(\mathbf{d}-\mathbf{f})$. $3 \mathrm{M}$ conditioning trial (a): threeway repeated measures ANOVA with Geisser-Greenhouse correction and Tukey's posthoc analysis revealed a significant effect of inter-trial interval $\left[F_{(3.200,89.59)}=67.91, p<0.0001\right]$, no significant effect of $h \alpha \mathrm{S}^{\mathrm{A} 53 \mathrm{~T}}$ genotype $\left[F_{(1,28)}=2.123, p=0.1562\right]$, no significant effect of $\mathrm{mTau}^{-/-}$genotype $\left[F_{(1,28)}=0.2536, p=0.6185\right]$, and no significant inter-trial interval $* \mathrm{~h}^{\mathrm{S}} \mathrm{S}^{\mathrm{A} 53 \mathrm{~T}} * \mathrm{mTau}^{-1-}$ interaction $\left[F_{(4,112)}=1.075, p=0.3723\right]$. $6 \mathrm{M}$ conditioning trial $(\mathbf{d})$ : three-way repeated measures ANOVA with Geisser-Greenhouse correction and Tukey's posthoc analysis revealed a significant effect of intertrial interval $\left[F_{(3.175,120.6)}=52.72, p<0.0001\right]$, a significant effect of $\mathrm{h} \alpha \mathrm{S}^{\mathrm{A} 53 \mathrm{~T}}$ genotype $\left[F_{(1,38)}=5.429, p=0.0252\right]$, no significant effect

in both short- and long-term spatial learning and memory (Suppl. Figure 3b, Online Resources). In TgA53T mice, Lewy-like amyloid intraneuronal accumulations of $h \alpha S$ are found primarily the dorsal midbrain, cerebellar nuclei, brainstem, and spinal cord, accompanied by astrogliosis but no neurodegeneration [65]. However, these neuropathological changes are absent in cortical and limbic system structures, including the hippocampus and amygdala, of TgA53T mice brains [65] suggesting that $\mathrm{h} \alpha \mathrm{S}^{\mathrm{A} 53 \mathrm{~T}}$-mediated neuronal dysfunction can occur in the absence of aggregate formation. This observation is consistent with another h $\alpha \mathrm{S}^{\mathrm{A} 53 \mathrm{~T}}$ expressing transgenic mouse line that develops motor and gait deficits but no $\alpha \mathrm{S}$-positive intracellular inclusions [38].
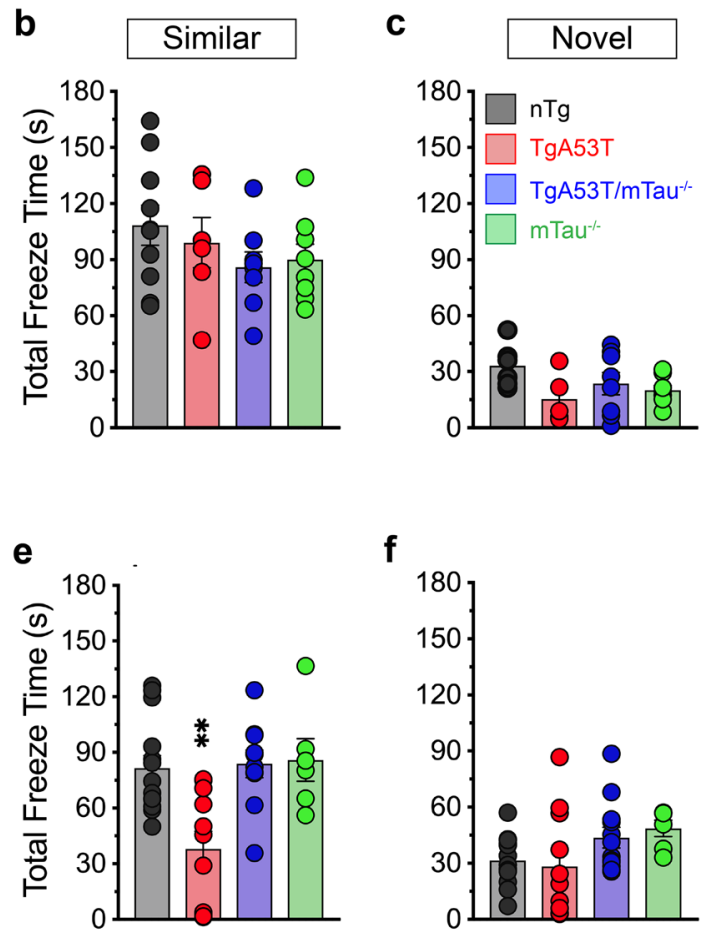

f

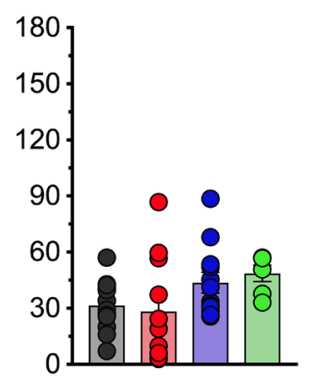

of $\mathrm{mTau}^{-/-}$genotype $\left[F_{(1,38)}=0.7273, p=0.3991\right]$, and no significant inter-trial interval $* \mathrm{~h} \alpha \mathrm{S}^{\mathrm{A} 53 \mathrm{~T} *} \mathrm{mTau}^{-/-}$interaction $\left[F_{(4,152)}=2.257\right.$, $p=0.0655]$. Percent of time spent freezing during conditioning trials (a, d) show similar responses in all genotypes. When mice are exposed to the similar environment, all genotypes show similar freezing responses at $3 \mathrm{M}(\mathbf{b})$, while $6 \mathrm{M}$ TgA53T mice freeze less than controls (e) [one-way ANOVA with Tukey's posthoc analysis: $\left.F_{(3,37)}=7.538, p=0.0005\right]$, indicating defective CFC. In contrast, $6 \mathrm{M}$ $\mathrm{TgA} 53 \mathrm{~T} / \mathrm{mTau}^{-/-}$mice show normal memory (e). Responses to the novel environment are not different between groups at both $3 \mathrm{M}(\mathbf{c})$ and $6 \mathrm{M}(\mathbf{f}) .3 \mathrm{M}: n_{\mathrm{nTg}}=8 ; n_{\mathrm{TgA} 53 \mathrm{~T}}=7 ; n_{\mathrm{TgA} 53 \mathrm{~T} / \mathrm{mTau}}^{-/-}=8 ; n_{\mathrm{mTau}}^{-/}=9.6 \mathrm{M}$ : $n_{\mathrm{nTg}}=13 ; n_{\mathrm{TgA} 53 \mathrm{~T}}=11 ; n_{\mathrm{TgA} 53 \mathrm{~T} / \mathrm{mTau}}^{-/-}=10 ; n_{\mathrm{mTau}}^{-/-}=8$. One- and threeway ANOVA: ${ }^{* *} p<0.01$. ns not significant. Error bars represent mean \pm SEM

\section{Presymptomatic motor hyperactivity of TgA53T mice is tau-independent}

Our results so far indicate that removing tau expression restores learning and memory deficits in TgA53T mice, particularly those associated with intact hippocampal function. However, TgA53T mice exhibit other presymptomatic abnormalities in advance of overt $\alpha$-synucleinopathy-associated motor dysfunction presentation. In particular, TgA53T mice, but not $\mathrm{TgWT}$ and $\mathrm{TgA} 30 \mathrm{P}$, exhibit spontaneous locomotor hyperactivity associated with increased striatal D1 dopamine receptor sensitivity $[41,116,119]$. Thus, we tested whether endogenous tau was required for $h \alpha \mathrm{S}^{\mathrm{A} 53 \mathrm{~T}}$-dependent hyperactivity. As expected, TgA53T mice exhibit a progressive increase in locomotor hyperactivity as measured by distance 

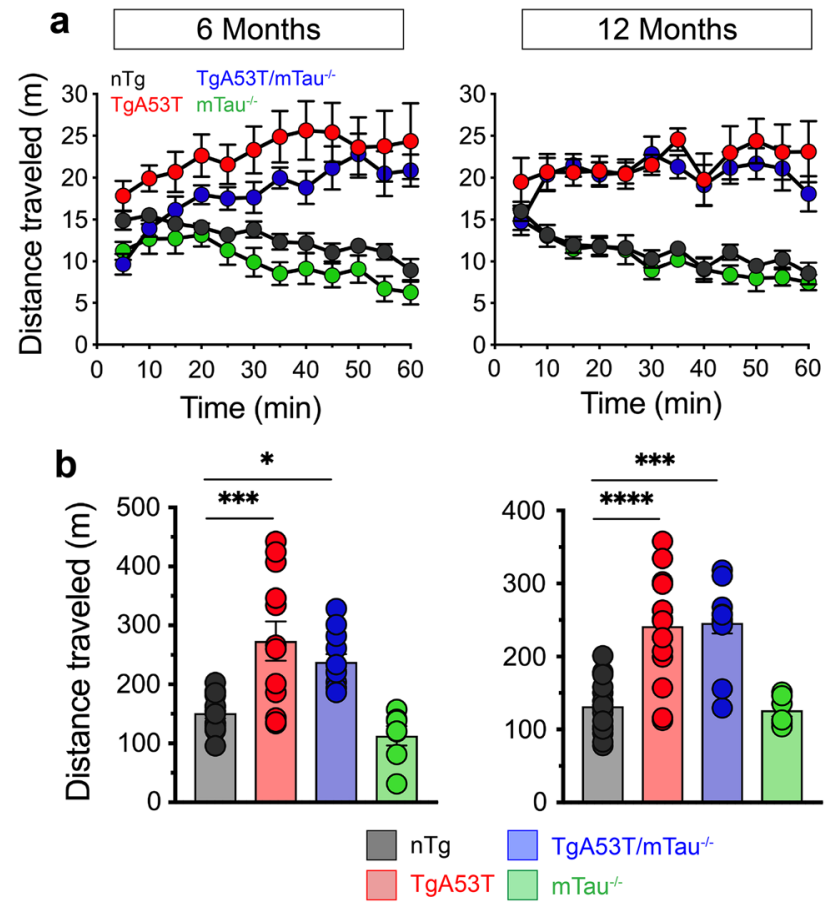

Fig. 3 Locomotor hyperactivity in the TgA53T model is tauindependent. a Distance traveled (m), binned into 5-min intervals, for the entire 60-min activity trial. b Summary graph of total distance traveled during the entire 60-min trial. TgA53T and TgA53T/ $\mathrm{mTau}^{-/-}$mice exhibit increases activity compared to controls (nTg and $\left.\mathrm{mTau}^{-l-}\right)$. 6 months $(6 \mathrm{M}): F_{(3,40)}=11.47(p<0.0001)$, oneway ANOVA with Tukey's posthoc analysis. 12 months (12M): $F_{(3,47)}=19.28(p<0.0001)$, one-way ANOVA with Tukey's posthoc analysis. $6 \mathrm{M}: \quad n_{\mathrm{nTg}}=11 ; n_{\mathrm{TgA} 53 \mathrm{~T}}=12 ; n_{\mathrm{TgA} 53 \mathrm{~T} / \mathrm{mTau}}^{-/-}=11 ; n_{\mathrm{mTau}}^{-/-}=9$. $12 \mathrm{M}: \quad n_{\mathrm{nTg}}=13 ; \quad n_{\mathrm{TgA} 53 \mathrm{~T}}=9 ; \quad n_{\mathrm{TgA} 53 \mathrm{~T} / \mathrm{mTau}}^{-l-}=11 ; \quad n_{\mathrm{mTau}}^{-l-}=8 . \quad$ Oneway ANOVA: $* p<0.05$ and $* * * p<0.001$. Error bars represent mean \pm SEM

traveled in the open-field arena at 6 and 12 months. This hyperactivity was tau-independent, as $\mathrm{TgA} 53 \mathrm{~T}$ and $\mathrm{TgA53T} /$ $\mathrm{mTau}^{-1-}$ mice exhibit similar levels of hyperactivity (Fig. 3a, b). While tau is required for mutant $\alpha \mathrm{S}$-mediated deficits in hippocampal function, we conclude that mutant $\alpha \mathrm{S}$-driven abnormalities associated with nigrostriatal circuitry appear tau-independent, suggesting a cell-type specificity of pathologic interactions between $\alpha \mathrm{S}$ and tau.

\section{Tau is required for A53T aS-linked impairments in excitatory and evoked neuronal activity}

In our model for how mutant $\alpha \mathrm{S}$ produces cognitive deficits, we propose that mutant $\alpha \mathrm{S}$ causes tau-dependent postsynaptic deficits characterized by the loss of AMPAR and subsequent deficits in hippocampal glutamatergic signaling, LTP, and memory impairments [110]. However, it is unknown if these pathways are directly interrelated. We, therefore, examined if endogenous tau expression was also required for $\alpha \mathrm{S}$-mediated synaptic deficits using acute hippocampal slice recordings [110]. Furthermore, to determine if these neurophysiological deficits in TgA53T neurons are progressive, we examined hippocampal slices from mice at 2-3 months of age, where animals have intact cognition, and 5-6 months of age, where mice first display impairments in CFC and YM. Consistent with our previous study, neurons from all mice show similar profiles in analysis of basal synaptic transmission at both age points, including analysis of input/output curves and paired-pulse facilitation (Fig. 4a-f). Analysis of synaptic fatigue shows that neurons lacking tau, either $\mathrm{mTau}^{-1-}$ or $\mathrm{TgA} 53 \mathrm{~T} / \mathrm{mTau}^{-/-}$, exhibit variable attenuation of stimulusdependent reductions in EPSC (excitatory postsynaptic current) amplitude, suggesting that tau may be involved in the regulation of high-frequency synaptic transmission under physiological conditions (Fig. 4f). Neurons from 6-month-old TgA53T mice exhibit reduced synaptic strength as measured by comparing AMPAR currents to NMDA receptor (NMDAR) currents (AMPA/NMDA ratio) (Fig. 4g, h). By contrast, neurons from 2 to 3-month-old TgA53T mice show a normal AMPA/NMDA ratio when compared to nTg littermate controls (Fig. 4g, h), indicating that $\mathrm{h} \alpha \mathrm{S}^{\mathrm{A} 53 \mathrm{~T}}$-mediated reductions in synaptic strength are progressive. Significantly, loss of tau expression in $\mathrm{TgA} 53 \mathrm{~T} / \mathrm{mTau}^{-/-}$reversed TgA53T-associated reductions in the AMPA/NMDA ratio (Fig. $4 \mathrm{~g}-\mathrm{i}$ ) providing the first ex vivo confirmation that tau mediates mutant $\alpha \mathrm{S}$-driven deficits in synaptic function and that these deficits coincide with onset of cognitive dysfunction.

Overexpression of synuclein-family proteins including $h \alpha S^{\mathrm{WT}}, \mathrm{h} \alpha \mathrm{S}^{\mathrm{A} 53 \mathrm{~T}}$, and $\beta$-synuclein $(\beta \mathrm{S})$ has been shown to reduce presynaptic vesicle release and neurotransmission [81]. However, $h \alpha \mathrm{S}^{\mathrm{A} 53 \mathrm{~T}}$ causes reductions in both spontaneous pre- and postsynaptic activities without detectable synapse loss [110]. Thus, we examined if tau expression modulates h $\alpha \mathrm{S}^{\mathrm{A} 53 \mathrm{~T}}$ reductions in synaptic activity by analyzing spontaneous neurotransmitter release and synaptic activity via recording of mini excitatory postsynaptic currents (mEPSCs). mEPSC frequency, reflecting the probability of neurotransmitter release from presynaptic vesicles, is reduced in $\mathrm{TgA53T}$ neurons at both $2-3$ months and 5-6 months of age, confirming that inhibition of neurotransmission is a direct, primary synaptic effect of $\alpha \mathrm{S}$ expression (Fig. 5a, c, d). More importantly, mEPSC amplitude, reflecting postsynaptic AMPAR function, was comparable between TgA53T and nTg neurons at 2-3 months of age, but shows significant reductions in slices from 5- to 6-month-old animals (Fig. 5b-d). These results, similar to memory deficits, indicate that postsynaptic deficits in $\mathrm{TgA}$ A3 T neurons are progressive with aging. Both mEPSC amplitude and frequency measured in neurons from $\mathrm{TgA} 53 \mathrm{~T} / \mathrm{mTau}^{-1-}$ slices are not different from $\mathrm{nTg}$ and $\mathrm{mTau}^{-/-}$controls, demonstrating that $h \alpha \mathrm{S}^{\mathrm{A} 53 \mathrm{~T}}$-mediated pre and postsynaptic deficits 

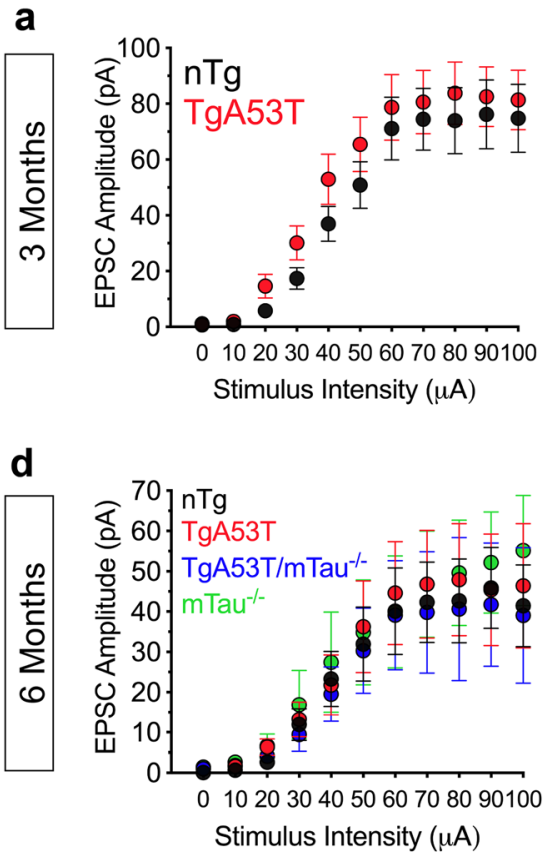
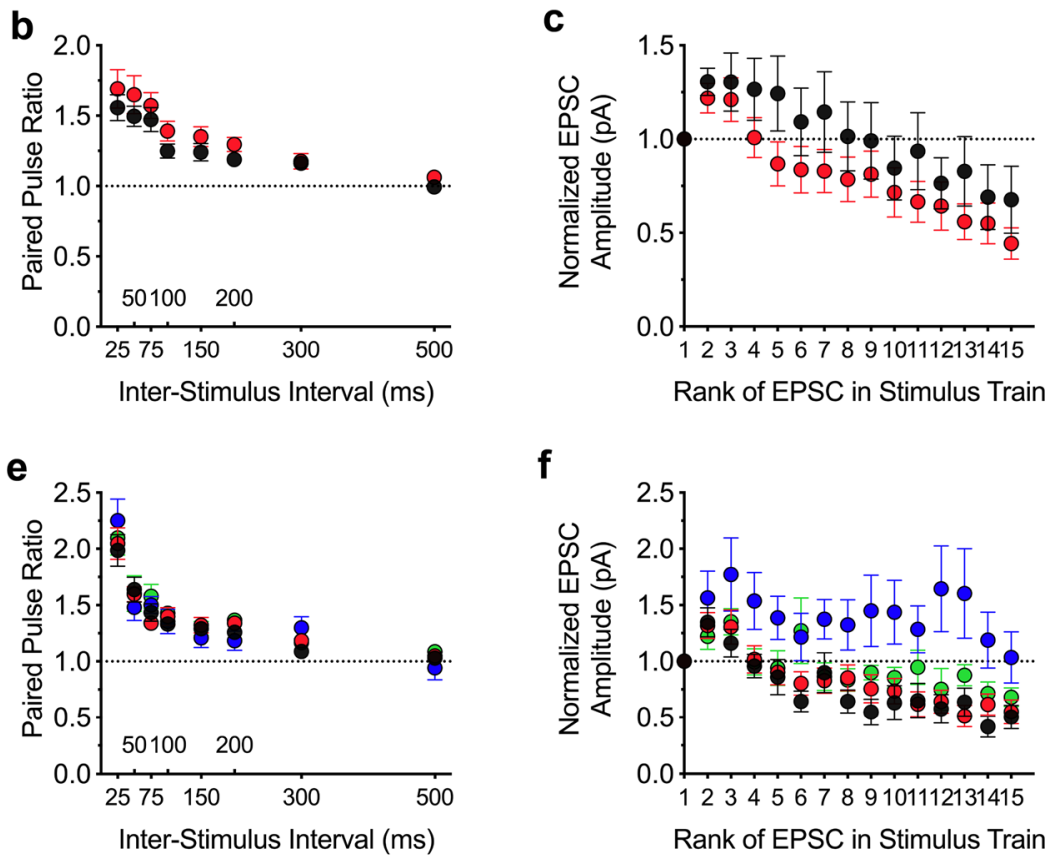

f

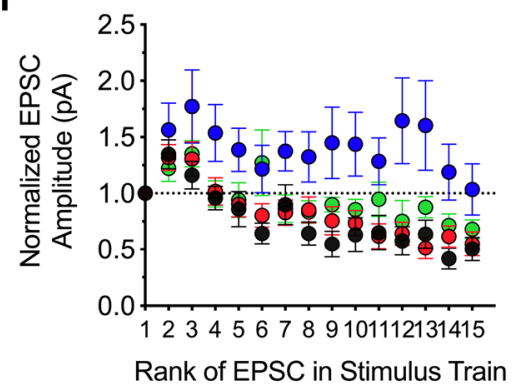

g

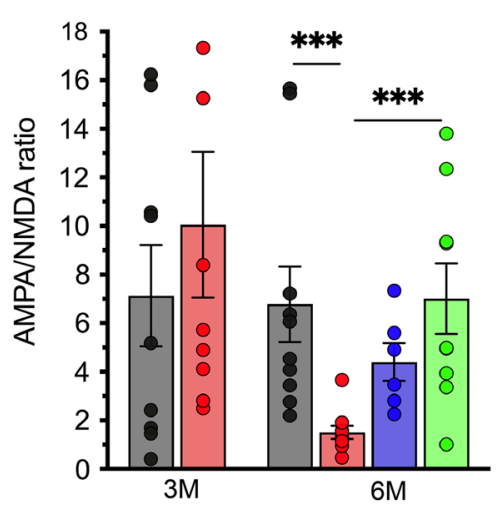

h
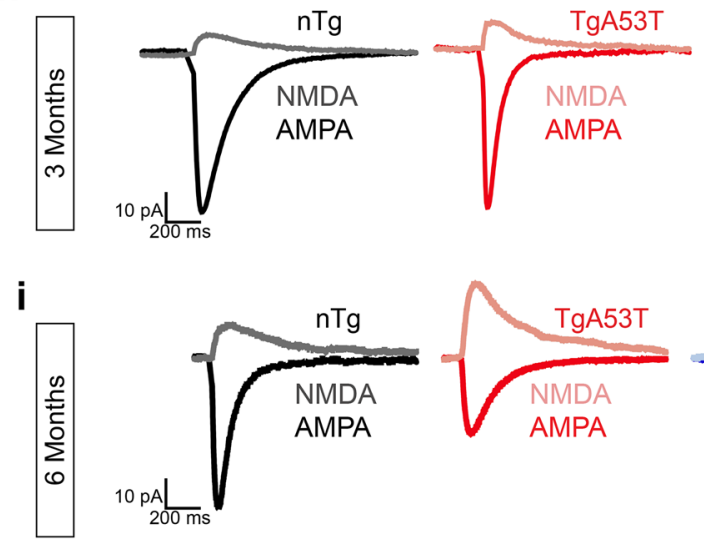

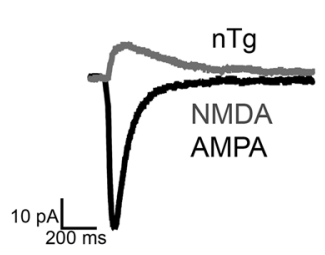

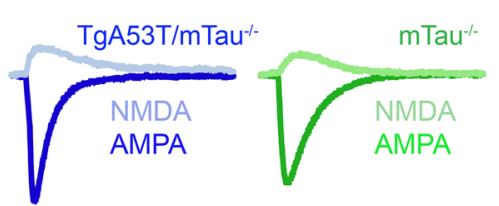

Fig. 4 Tau is required for progressive loss of AMPAR-mediated neurotransmission in TgA53T neurons. Core excitatory postsynaptic current (EPSC) synaptic parameters assed in acute hippocampal slices from animals at 2-3 (3 months, $3 \mathrm{M})$ and 5-6 (6 months, $6 \mathrm{M})$ months of age, respectively: a, d Input-output curve. b, e Short-term potentiation measured via paired-pulse facilitation. c, f Short-term depression analyzed through synaptic fatigue. $3 \mathrm{M}$ : input-output: genotype $F_{(1,262)}=4.790, p=0.0295$, stimulus intensity $F_{(10,262)}=28.19$, $p<0.0001$, genotype*stimulus intensity interaction $F_{(10,262)}=0.1596$, $p=0.9985$; paired pulse: genotype $F_{(1,176)}=7.422, p=0.0071$; interstimulus interval $F_{(7,176)}=15.34, p<0.0001$; genotype*inter-stimulus interval interaction $F_{(7,176)}=0.1785, p=0.9894$; synaptic fatigue: genotype $F_{(1,360)}=14.26, p=0.0002$, EPSC in train $F_{(14,360)}=4.611$, $p<0.0001$, genotype*EPSC in train interaction $F_{(14,360)}=0.2468$, $p=0.9978$; all two-way ANOVA with Sidak's posthoc analysis. 6M: Input-output: genotype $F_{(3,407)}=0.7457, p=0.5253$, stimulus intensity $F_{(10,407)}=13.90, p<0.0001$, genotype*stimulus intensity interaction $F_{(30,407)}=0.05744, p>0.9999$; paired pulse: genotype $F_{(3,318)}=0.8501, \quad p=0.4674$, inter-stimulus interval $F_{(7,318)}=51.83, p<0.0001$, genotype*inter-stimulus interval inter- action $F_{(7.318)}=0.7178, p=0.8147$; synaptic fatigue: genotype $F_{(3,645)}=42.33, p<0.0001$, EPSC in train $F_{(14,645)}=5.048, p<0.0001$, genotype*EPSC in train interaction $F_{(42,645)}=0.7835, p=0.8360$; all two-way ANOVA with Tukey's posthoc analysis. 3M (mice/ slices/cells): $n_{\mathrm{nTg}}=3 / 7 / 13 ; n_{\mathrm{TgA} 53 \mathrm{~T}}=3 / 7 / 13.6 \mathrm{M}$ (mice/slices/cells): $n_{\mathrm{nTg}}=5 / 10 / 11 ; n_{\mathrm{TgA} 53 \mathrm{~T}}=5 / 9 / 11 ; n_{\mathrm{TgA} 53 \mathrm{~T} / \mathrm{mTau}}^{-/-}=4 / 8 / 8 ; n_{\mathrm{mTau}}^{-/-}=4 / 11 / 11$. Except for modest reductions in synaptic fatigue associated with the $\mathrm{mTau}^{-/-}$genotype (f), there are no obvious differences in evoked synaptic parameters. $\mathbf{g}$ Ratio of amplitude of AMPA:NMDA currents in CA1 pyramidal neurons from $\mathrm{nTg}$ and $\mathrm{TgA} 53 \mathrm{~T}$ mice at $3 \mathrm{M}$, and $\mathrm{nTg}$, TgA53T, $\mathrm{TgA} 53 \mathrm{~T} / \mathrm{mTau}^{-1-}$, and $\mathrm{mTau}^{-/-}$at 6M. AMPA/NMDA: $F_{(3,31)}=5.044, p=0.0058$, by one-way ANOVA with Tukey's posthoc analysis. $3 \mathrm{M}$ (mice/slices/cells): $n_{\mathrm{nTg}}=3 / 6 / 9$ cells; $n_{\mathrm{TgA} 53 \mathrm{~T}}=3 / 6 / 9$ cells. $6 \mathrm{M}$ (mice/slices/cells): $n_{\mathrm{nTg}}=7 / 9 / 10$ cells; $n_{\mathrm{TgA} 53 \mathrm{~T}}=4 / 10 / 10$ cells; $n_{\mathrm{TgA} 53 \mathrm{~T} / \mathrm{mTau}}^{-/-}=3 / 7 / 7$ cells; $n_{\mathrm{mTau}}^{--}=3 / 8 / 9$ cells . Example AMPA and NMDA current traces from $3 \mathrm{M}$ (h) and $6 \mathrm{M}$ groups (i). While the AMPA/NMDA ratio is normal in 3-month-old TgA53T neurons, there is significant reduction in 6-month-old neurons. $t$ test, and oneand two-way ANOVA: $* p<0.05$ and $* * * p<0.001$. Error bars represent mean \pm SEM 

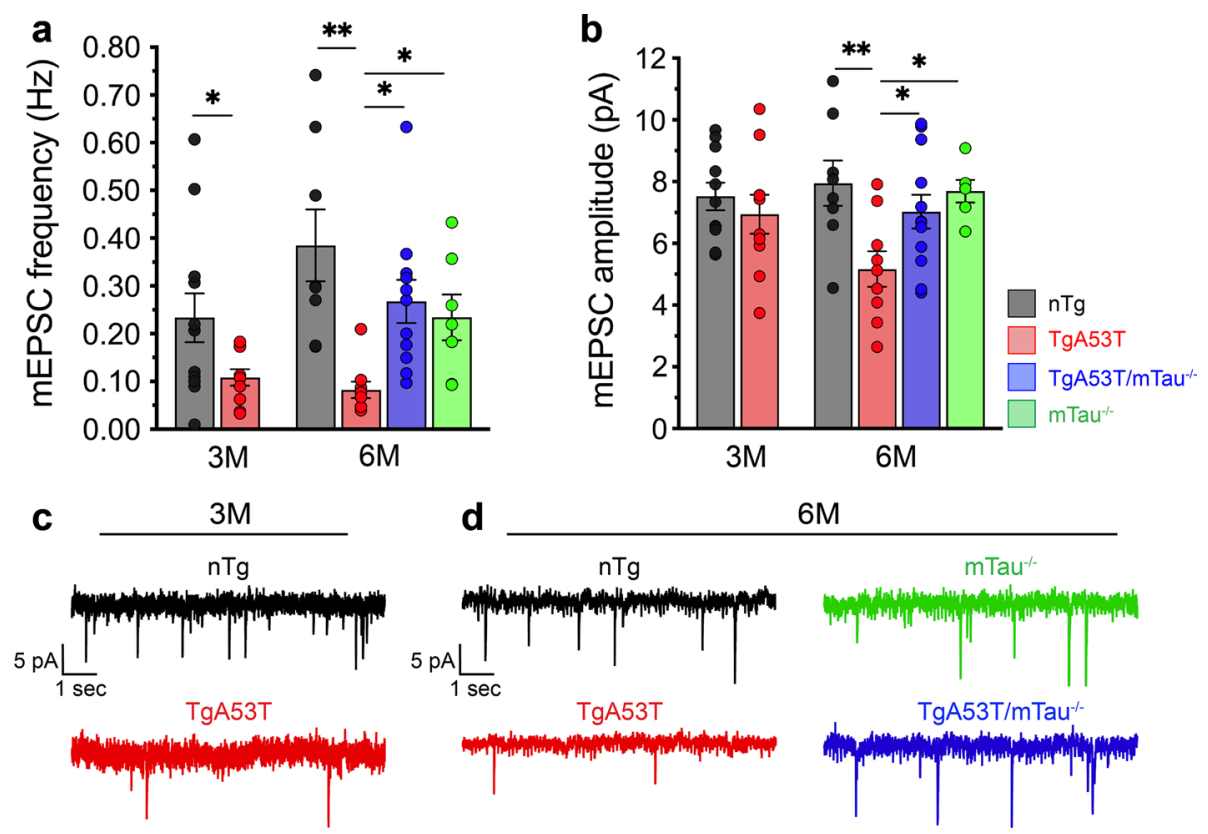

Fig. 5 Spontaneous synaptic activity deficits in TgA53T neurons are reversed by loss of mTau expression. Spontaneous recordings of mini excitatory postsynaptic currents (mEPSCs) from CA1 pyramidal neurons in acute hippocampal slices were recorded from and analyzed for frequency (a) and amplitude (b) of mEPSCs from mice at 2-3 months $(3 \mathrm{M})$ and $5-6$ months $(6 \mathrm{M})$ of age. $3 \mathrm{M}$ mEPSC frequency: $t=2.32$, $d f=13.51, p=0.0364$, by unpaired $t$ test with Welch's correction. 6M mEPSC frequency: $F_{(3,31)}=6.213, p=0.0020$, by oneway ANOVA and Tukey's posthoc analysis. 6M mEPSC amplitude: $F_{(3,31)}=4.187, p=0.0134$, by one-way ANOVA and Tukey's

require tau expression. The fact that $\mathrm{mTau}^{-/-}$neurons were not different from $\mathrm{nTg}$ neurons in these measures demonstrates that the reversal of mutant $\alpha \mathrm{S}$-dependent effects in $\mathrm{TgA} 53 \mathrm{~T} / \mathrm{mTau}^{-/-}$neurons is not due to simple additive effects.

It is possible that the findings in acute hippocampal slices could involve tau-dependent alterations in circuit development or compensation. To account for this possibility, we used dissociated hippocampal neuronal cultures to test whether loss of tau can reverse the synaptic changes observed in TgA53T neurons [110]. Neurophysiological analysis of primary cultures from $\mathrm{TgA} 53 \mathrm{~T}$ and $\mathrm{TgA} 53 \mathrm{~T} /$ $\mathrm{mTau}^{-1-}$ shows that loss of tau expression blocks the effects of mutant $\alpha \mathrm{S}$ overexpression (Suppl. Figure 4, Online Resources), implicating tau as a direct mediator of mutant $\alpha S$-induced pre- and postsynaptic changes.

Having established tau as a mediator of $h \alpha \mathrm{S}^{\mathrm{A} 53 \mathrm{~T}}$-driven postsynaptic deficits in spontaneous neurotransmission, we next asked if tau contributes to A53T $\alpha$ S-mediated deficits in long-term plasticity by evaluating hippocampal LTP induction [71]. Consistent with intact spatial learning and memory (Fig. 2; Suppl. Figure 2, Online Resources), LTP in $\mathrm{TgA} 53 \mathrm{~T}$ mice at $2-3$ months is normal when compared posthoc analysis. c Example mEPSC traces from 2 to 3-monthold $\mathrm{TgA} 53 \mathrm{~T}$ and nTg littermate controls. 3M (mice/slices/cells): $n_{\mathrm{nTg}}=3 / 7 / 11 ; n_{\mathrm{TgA} 53 \mathrm{~T}}=3 / 6 / 10.6 \mathrm{M}$ (mice/slices/cells): $n_{\mathrm{nTg}}=5 / 8 / 8$ cells; $n_{\mathrm{TgA} 53 \mathrm{~T}}=3 / 7 / 9$ cells $; n_{\mathrm{TgA} 53 \mathrm{~T} / \mathrm{mTau}}^{-/}=5 / 11 / 12$ cells $; n_{\mathrm{mTau}}^{-1}=3 / 6 / 7$ cells. d Example mEPSC traces from 5 to 6-month-old nTg, TgA53T, $\mathrm{TgA} 53 \mathrm{~T} / \mathrm{mTau}^{-1-}$, and $\mathrm{mTau}^{-1-}$ mice. The results show that reductions in mEPSC frequency in $\mathrm{TgA53T}$ neurons is not progressive from $3 \mathrm{M}$ to $6 \mathrm{M}$, while reductions in mEPSC amplitude in $\mathrm{TgA} 53 \mathrm{~T}$ neurons is age-progressive over this time frame. $t$ test and one-way ANOVA: $* p<0.05$ and $* * p<0.01$. Error bars represent mean \pm SEM

to age-matched nTg littermates (Fig. 6a, c, d). At 6 months, cognitively impaired TgA53T mice display tau-dependent memory deficits (Fig. 2; Suppl. Figure 3, Online Resources) and LTP deficits (Fig. 6b, c, e). Taken together, our findings thus far demonstrate that tau is required for TgA53Tassociated progressive impairments in synaptic activity and plasticity and spatial learning and memory. Moreover, our results show that presynaptic effects due to $\alpha \mathrm{S}$ overexpression are not sufficient to cause memory deficits, suggesting that altered postsynaptic glutamatergic signaling is required for cognitive dysfunction in the TgA53T model.

\section{Tau does not alter expression or oligomerization of aS in forebrains of TgA53T mice}

Post-translational modifications of $\alpha \mathrm{S}$ are believed to be integral to PD pathophysiology. Levels of aggregate-promoting C-terminally truncated $\alpha \mathrm{S}(\alpha \mathrm{S} \Delta \mathrm{C})$ are increased by familial PD-linked A30P and A53T missense mutations [66]. Furthermore, phosphorylated $\alpha \mathrm{S}$ at Serine 129 (pSer129) is an accepted marker of $\alpha \mathrm{S}$ pathology in situ [32, 96]. Thus, we asked if tau-dependent synaptic and memory deficits and cognitive decline in $\mathrm{TgA} 53 \mathrm{~T}$ mice were 

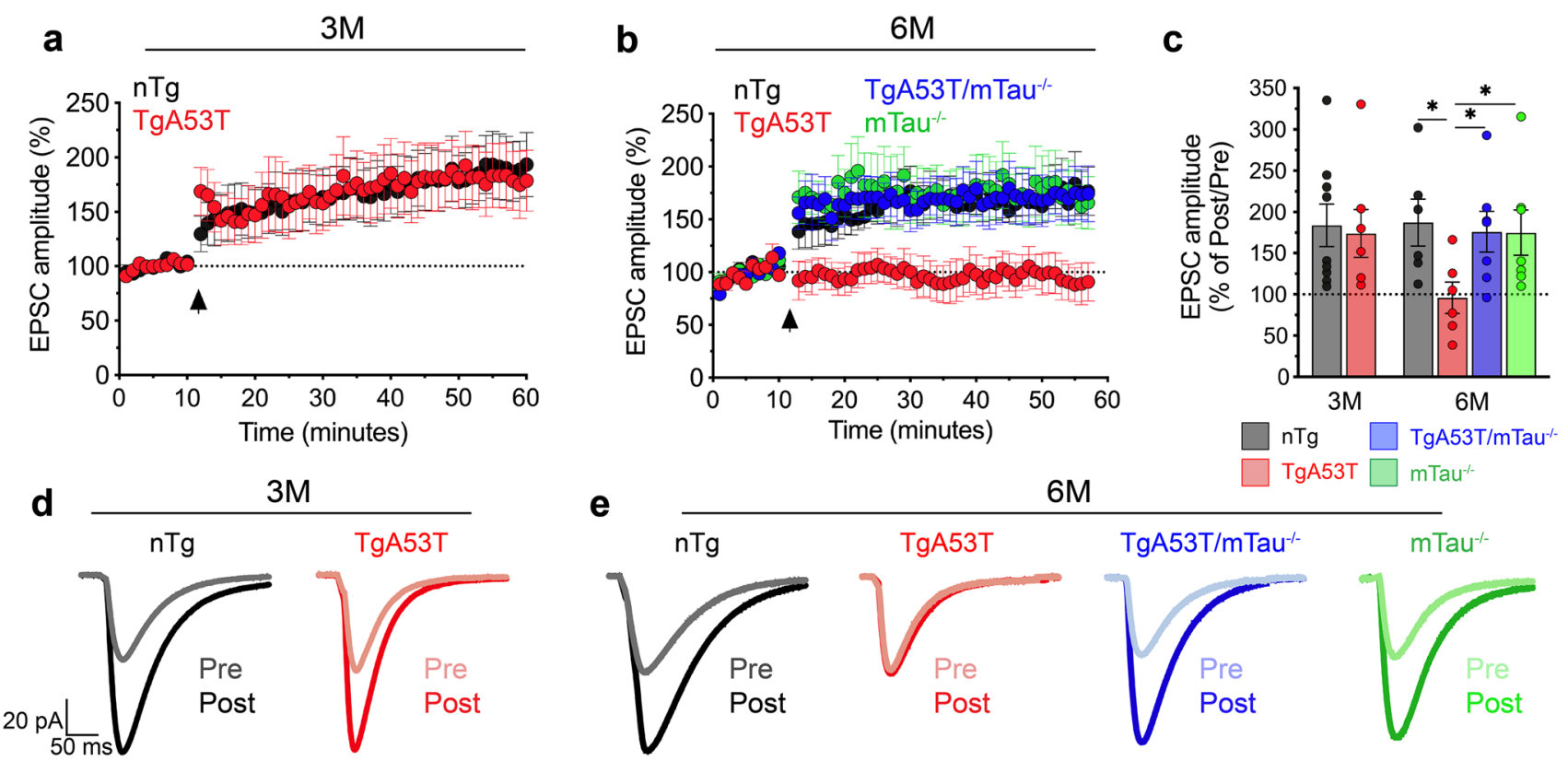

Fig. 6 Progressive deficits in long-term potentiation in TgA53T neurons are tau-dependent and correlate with onset of cognitive impairments. Excitatory postsynaptic currents (EPSC) recorded via whole-cell recordings from hippocampal CA1 pyramidal neurons during long-term potentiation induced by high-frequency stimulation (HFS) of Schaffer collaterals of animals at 2-3 months (3M) (a) and 5-6 months $(6 \mathrm{M})$ of age (b). Arrowhead indicates application of HFS. c EPSC amplitudes $45 \mathrm{~min}$ following HFS (post), relative to baseline established prior to HFS (pre), from both $3 \mathrm{M}$ to $6 \mathrm{M}$ animals. 6M LTP EPSC: $F_{(3,22)}=2.584, p=0.0262$, by one-way ANOVA

due to alterations in hippocampal and cortical $\alpha \mathrm{S}$ expression, increased pathogenic $\alpha \mathrm{S}$ modifications, $\alpha \mathrm{S}$ oligomer accumulation, or abnormal tau accumulation. Immunoblot analysis demonstrates that total hippocampal and cortical tau levels were not different between $\mathrm{nTg}$ and $\mathrm{TgA}$ 53T lysates, indicating that alterations in tau expression are not responsible for tau-dependent deficits in TgA53T mice and neurons. Conversely, the loss of tau also did not alter total $\alpha \mathrm{S}$ levels in $\mathrm{nTg}$ or TgA53T mice (Fig. 7a, b; Suppl. Figure 5a, c, Online Resources). In addition, both $\alpha \mathrm{S} \Delta \mathrm{C}$ and $\mathrm{pSer} 129 \alpha \mathrm{S}$ levels were unaffected by tau expression (Fig. 7a, b). Finally, consistent with the previous studies $[22,65,66]$, very little levels of detergent-insoluble $\alpha \mathrm{S}$ are present in hippocampal lysates and levels of detergent-insoluble $\alpha \mathrm{S}$ are not altered by tau expression (Suppl. Figure 6a, b, Online Resources).

Analysis of total tau expression via Tau 5 antibody indicates that $\mathrm{TgA} 53 \mathrm{~T}$ cortices and hippocampi express comparable tau levels to that of nTg brains (Fig. 7a, b; Suppl. Figure 5a, c, Online Resources). To determine if the synaptic deficits observed in $\mathrm{TgA53T}$ neurons were associated with increased tau phosphorylation [110], expression of phosphorylated tau species as recognized by AT8, CP13, and PHF1 antibodies was determined via concurrent immunoblot and Tukey's posthoc analysis. $3 \mathrm{M}$ (mice/slices/cells): $n_{\mathrm{nTg}}=4 / 9 / 9$ cells; $n_{\mathrm{TgA} 53 \mathrm{~T}}=4 / 7 / 7$ cells. $6 \mathrm{M}$ (mice/slices/cells): $n_{\mathrm{nTg}}=5 / 6 / 6$ cells; $n_{\mathrm{TgA} 53 \mathrm{~T}}=5 / 6 / 6$ cells; $n_{\mathrm{TgA} 53 \mathrm{~T} / \mathrm{mTau}}^{-/-}=3 / 7 / 7$ cells; $n_{\mathrm{mTau}}^{-1-}=3 / 7 / 7$ cells . These results show that TgA53T neurons exhibit normal LTP at 3M but severe LTP deficits at $6 \mathrm{M}$. Furthermore, TgA53T/mTau ${ }^{-1-}$ neurons exhibit normal LTP at $6 \mathrm{M}$. d, e Example EPSC traces from LTP experiments. Presented here are pre- and post-HFS in $3 \mathrm{M}$ neurons (d) and 6M neurons (e). $t$ test and one-way ANOVA: * $p<0.05$. Error bars represent mean $\pm \mathrm{SEM}$

analysis [56]. These results demonstrate that $\mathrm{TgA} 33 \mathrm{~T}$ brains exhibit modest, but significantly increased levels of AT8, CP13, and PHF1-positive phosphorylated tau (Suppl. Figure $6 \mathrm{c}$, e, Online Resources). As expected, no immunoreactivity to tau-related epitopes is observed in $\mathrm{mTau}^{-/-}$animals. These results are consistent with our hypothesis that $h \alpha \mathrm{S}^{\mathrm{A} 53 \mathrm{~T}}$ drives synaptic deficits by phosphorylation-dependent mislocalization of tau into dendritic spines [110].

$\alpha \mathrm{S}$ and tau also have the capacity to induce each other's aggregation and polymerization into fibrillar amyloid structures [36] and $\alpha \mathrm{S}$ oligomers can induce tau misfolding and downstream generation of oligomers [17, 34]. Thus, we next investigated if the levels of soluble $\alpha \mathrm{S}$ and/ or tau oligomers could be correlated with synaptic and memory deficits in TgA53T mice. In all cortical and hippocampal lysates, no general amyloid structures (OC), soluble oligomeric species (A11), or tau oligomers (T22) [62] were present at detectable levels (Fig. 7c, d; Suppl. Figure 7, Online Resources). As expected, a panel of antibodies against conformational-specific and higher order assemblies of $\alpha \mathrm{S}$ showed increased levels in TgA53T lysates. However, they did not reveal any changes as a function of tau expression: Syn33 (oligomers, dimers, and 

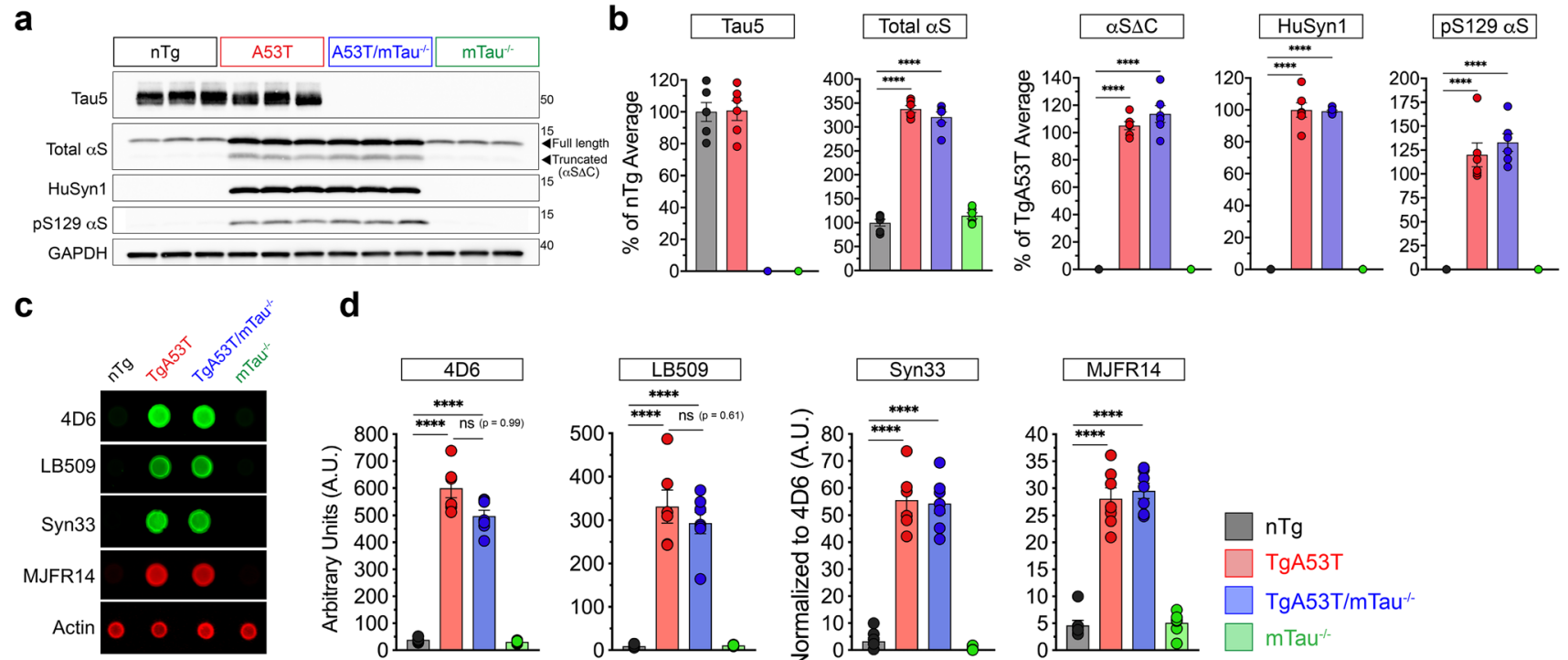

d
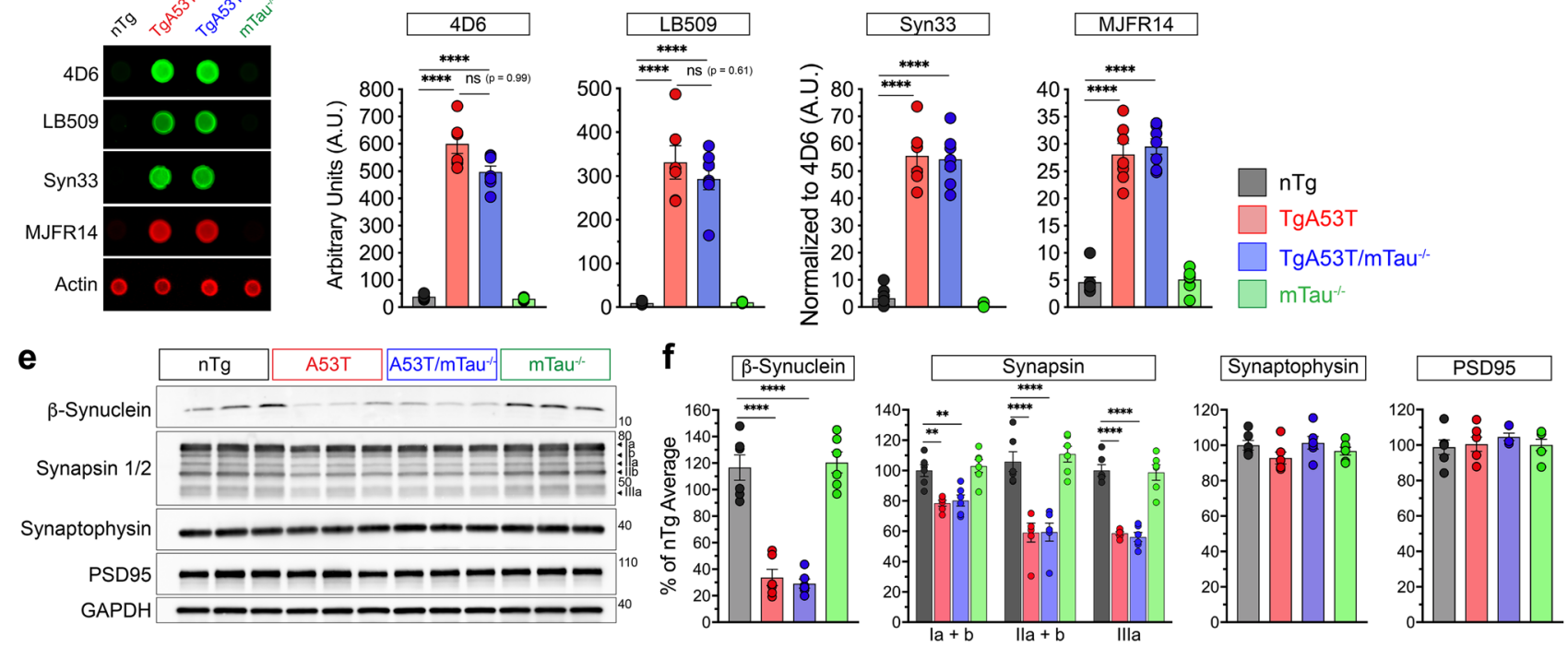

Fig. 7 Tau-dependent synaptic and cognitive deficits in TgA53T mice are independent of expression or aggregate-specific changes in $\alpha \mathrm{S}$ or key presynaptic proteins. a Representative western blot analysis of hippocampal lysates from 12-month-old mice. b Densitometry of hippocampal protein expression. For tau and total $\alpha S$ (full length), values were normalized to the average values for nTg samples within each gel. For truncated $\alpha \mathrm{S}(\alpha \mathrm{S} \Delta \mathrm{C})$, human $\alpha \mathrm{S}$ (HuSyn1), $\alpha \mathrm{S}$ phosphorylated at Ser129 (pS129 $\alpha \mathrm{S}$ ), values were normalized to the average densitometric values of $\mathrm{TgA53T}$ samples within each gel. For western blot densitometry: one-way ANOVA with Tukey's posthoc analysis. Total $\alpha \mathrm{S}: F_{(3,20)}=252.4, p<0.0001$. $\alpha \mathrm{S} \Delta \mathrm{C}: F_{(3,20)}=335.9, p<0.0001$. HuSyn1: $F_{(3,20)}=616.2, p<0.0001$. pS129 $\alpha \mathrm{S}: F_{(3,20)}=88.70, p<0.0001$. While $\alpha \mathrm{S}$-associated protein levels are increased in $\mathrm{TgA53 \textrm {T }}$ mice, the levels are not altered in $\mathrm{TgA} 53 \mathrm{~T} / \mathrm{mTau}^{-1-}$ mice. $N=6$ animals/genotype. c Representative dot blots from non-denatured 12-month-old hippocampal lysates for the epitopes associated with total $\alpha \mathrm{S}$ (4D6), human $\alpha \mathrm{S}$ (LB509), and various pathological $\alpha \mathrm{S}$ oligomers (Syn33, MJFR14). Dot blots for additional $\alpha \mathrm{S}$ oligomers and pathological tau are shown in Suppl. Figure 5 (Online Resources). d Dot blot densitometry for levels of total $\alpha \mathrm{S}$ (4D6) and human $\alpha \mathrm{S}$ (LB509), normalized to actin levels. For higher order $\alpha \mathrm{S}$ species, Syn33 and MJFR14, densitometry values were normalized to the average densitometric values of TgA53T samples within each gel. For all dot blot densitometry: one-way ANOVA with Tukey's posthoc analysis. 4D6: $F_{(3,23)}=232.9, p<0.0001$. LB509: $F_{(3,23)}=68.53, p<0.0001$. Syn33: $F_{(3,23)}=116.4, p<0.0001$. MJFR14: $F_{(3,23)}=101.1, p<0.0001 . N=8$ animals/genotype. While $\alpha \mathrm{S}$ and $\alpha \mathrm{S}$ oligomer species levels are increased in TgA53T mice, they are unchanged by tau removal in $\mathrm{TgA} 53 \mathrm{~T} / \mathrm{mTau}^{-1-}$ mice. e Representative western blot images of presynaptic and postsynaptic proteins of interest in 12-month-old hippocampi. f Densitometry of hippocampal protein expression. Values were normalized to the average values for nTg samples within each gel. For western blot densitometry: one-way ANOVA with Tukey's posthoc analysis. $\beta$-Synuclein: $F_{(3,20)}=49.86, p<0.0001$. Synapsin Ia + b: $F_{(3,20)}=8.501, p=0.0008$. Synapsin IIa + b. $F_{(3,20)}=9.482, p=0.0004$. Synapsin IIIa: $F_{(3,20)}=46.62, p<0.0001 . \quad \mathrm{N}=6$ animals/genotype. Densitometry shows that while $\beta$-synuclein and synapsin isoforms are decreased in $\mathrm{TgA53T}$ mice, they are not altered by loss of tau expression. Furthermore, the levels of synaptophysin and PSD95 are comparable in all animals, indicating a lack of synaptic loss. For all, values were normalized to the average densitometric values of nTg samples within each gel. One-way ANOVA: $* * p<0.01$ and $* * * * p<0.0001$. $n s$ not significant. Error bars represent mean \pm SEM higher molecular weight aggregates), F8H7 (oligomers from $70 \mathrm{kDa}$ and above), and MJFR-14-6-4-2 (soluble oligomeric and fibrillar structures) $[62,69,84,101]$. While the mutant $\alpha \mathrm{S}$-selective effects on synaptic function and behavioral deficits suggest that pathological $\alpha$ S species are involved, our results indicate that the tau-dependent effects are not due to simple modulation of $\alpha \mathrm{S}$ expression and $\alpha \mathrm{S}$ oligomerization. Collectively, based on our results, we propose that the effect of tau may be occurring downstream or independent of the pathological conversion of $\alpha \mathrm{S}$. 


\section{Memory deficits in TgA53T mice occurs in the absence of synaptic degeneration}

In vertebrates, $\alpha \mathrm{S}$ is a part of the larger synuclein gene family that include homologs $\beta$ - and $\gamma$-synuclein $[33,64$, 74]. $\beta$-Synuclein $(\beta S)$ can antagonize $\alpha \mathrm{S}$ aggregation and toxicity [44] and ameliorating endogenous $\beta S$ enhances pathological $\alpha \mathrm{S}$ phosphorylation and aggregation [30]. Consistent with the previous findings [112], expression of $\alpha \mathrm{S}$ is inversely correlated with $\beta \mathrm{S}$ accumulation in the brain (Fig. 7e, f; Suppl. Figure 5b, d, Online Resources). Interestingly, the reduction in cortical and hippocampal $\beta S$ expression of $\mathrm{TgA}$ A3 T mice is not rescued by removal of endogenous tau (Fig. 7e, f; Suppl. Figure 5b, d, Online Resources).

Other $\alpha \mathrm{S}$ transgenic mouse models that exhibit memory deficits are associated with various levels of neurodegenerative changes, including cortical $\alpha \mathrm{S}$ pathology and cortical and hippocampal synaptic loss [45, 57]. While cortical and hippocampal pathology are not robust features of the TgA53T model, we examined whether the taudependent memory deficits in the $\mathrm{TgA} 53 \mathrm{~T}$ model are due to loss of synapses by evaluating the protein abundance of presynaptic (synaptophysin) and postsynaptic (PSD95) proteins. Biochemically, there were no differences in the amounts of either synaptic proteins across the four genotypes assessed at 12 months of age (Fig. 7e, f; Suppl. Figure 5b, d, Online Resources). We next extended our biochemical findings with immunostaining to probe for changes in hippocampal and synaptic structure. TgA53T hippocampi at 12 months show similar hippocampal structure as compared to age-matched nTg littermates via staining for neuronal nuclei (NeuN; Suppl. Figure 8a, Online Resources), demonstrating that overt neuronal loss is not required for $h \alpha \mathrm{S}^{\mathrm{A} 53 \mathrm{~T}}$-mediated cognitive decline. Furthermore, confocal images of somatodendritic (MAP2), presynaptic (synaptophysin), and postsynaptic (PSD95) structures qualitatively indicate intact synaptic structures in cognitively impaired 12 month $\mathrm{TgA}$ 53 T mice compared to nTg littermates (Suppl. Figure 8b, Online Resources). Collectively, our results show that neither neuronal loss nor synaptic degradation is responsible for the $\alpha \mathrm{S}$-mediated cognitive dysfunction in TgA53T mice.

In light of an apparent intact synaptic integrity synapses in TgA53T mice, increased human wild-type or mutant $\alpha \mathrm{S}$ expression has been implicated in dysregulation of presynaptic function by selectively reducing levels of synapsins [61, 81]. Immunoblot analyses of cortical and hippocampal lysates confirm reduced levels of synapsin isoforms in TgA53T mice (Fig. 7e, f; Suppl. Figure 5b, d, Online Resources). However, suppressed synapsin levels were not restored by loss of tau expression in $\mathrm{TgA} 53 \mathrm{~T} / \mathrm{mTau}^{-/-}$brains, indicating that tau functions in a distinct pathway or downstream of synapsin expression (Fig. 7e, f; Suppl. Figure 5b, d, Online Resources). These results support our behavioral findings that $\alpha \mathrm{S}$-mediated presynaptic deficits alone are not sufficient for memory deficits.

\section{Synaptic and memory deficits in TgA53T mice associated with tau-dependent alterations in postsynaptic glutamate receptors}

The cellular and molecular mechanisms driving LTP are mediated by postsynaptic AMPAR and NMDAR [10, 71, 72]. Tau missorting to dendritic spines is associated with memory loss and impairments in postsynaptic AMPAR signaling in frontotemporal dementia and parkinsonism linked to chromosome 17 (FTDP-17), Alzheimer's disease (AD) $[47,77]$. We showed that $h \alpha \mathrm{S}^{\mathrm{A} 53 \mathrm{~T}}$-mediated tau missorting to dendritic spines is associated with calcineurindependent AMPAR internalization [110]. As the loss of hippocampal AMPARs likely contributes to deficits in LTP and memory, we sought to determine if reductions in AMPAR expression occurs in TgA53T mice. Immunoblot analysis displayed progressive reductions specific to hippocampal, but not cortical, AMPAR subunits (GluA1 and GluA2/3). Specifically, while AMPAR levels are not different between 3-month-old nTg and TgA53T mice, they are significantly reduced in $\operatorname{TgA53T}$ hippocampi at 6 and 12 months of age (Fig. 8a-c, f, g; Suppl. Figure 9, Online Resources). These $\mathrm{h} \alpha \mathrm{S}^{\mathrm{A53T}}$-mediated deficits are tau-dependent as TgA53T/ $\mathrm{mTau}^{-/-}$hippocampi displayed levels of AMPAR expression similar to nTg and $\mathrm{mTau}^{-1-}$ controls at 12 months of age. Thus, loss of hippocampal AMPAR levels correlates with age- and tau-dependent onset of synaptic and cognitive deficits. To determine the selectivity of AMPAR changes, we also examined NMDAR levels, receptors essential for LTP but not functionally altered by tau mislocalization to spines [47]. GluN1 and GluN2A expression remained unchanged in cognitively intact 3-month-old or impaired 6-monthold TgA53T mice compared to nTg controls (Fig. 8a-e; Suppl. Figure 9, Online Resources). GluN1 expression was increased in 12-month-old TgA53T hippocampi and cortices, but, unlike AMPAR subunit expression changes, was neither changed by the status of tau expression (Fig. 8d). Collectively, these results parallel our neurophysiological findings and further our proposal that the TgA53T model is associated with the selective impairments in hippocampal postsynaptic AMPAR signaling in a tau-dependent manner, while NMDARs are largely unaffected or slightly increased in multiple brain regions.

AD-associated amyloid- $\beta$ (A $\beta$ ) oligomers have been shown to alter postsynaptic signaling through binding to cellular prion protein $\left(\mathrm{PrP}^{\mathrm{C}}\right)$ that produces downstream Fyn activation and phosphorylation of the GluN2B subunit of 


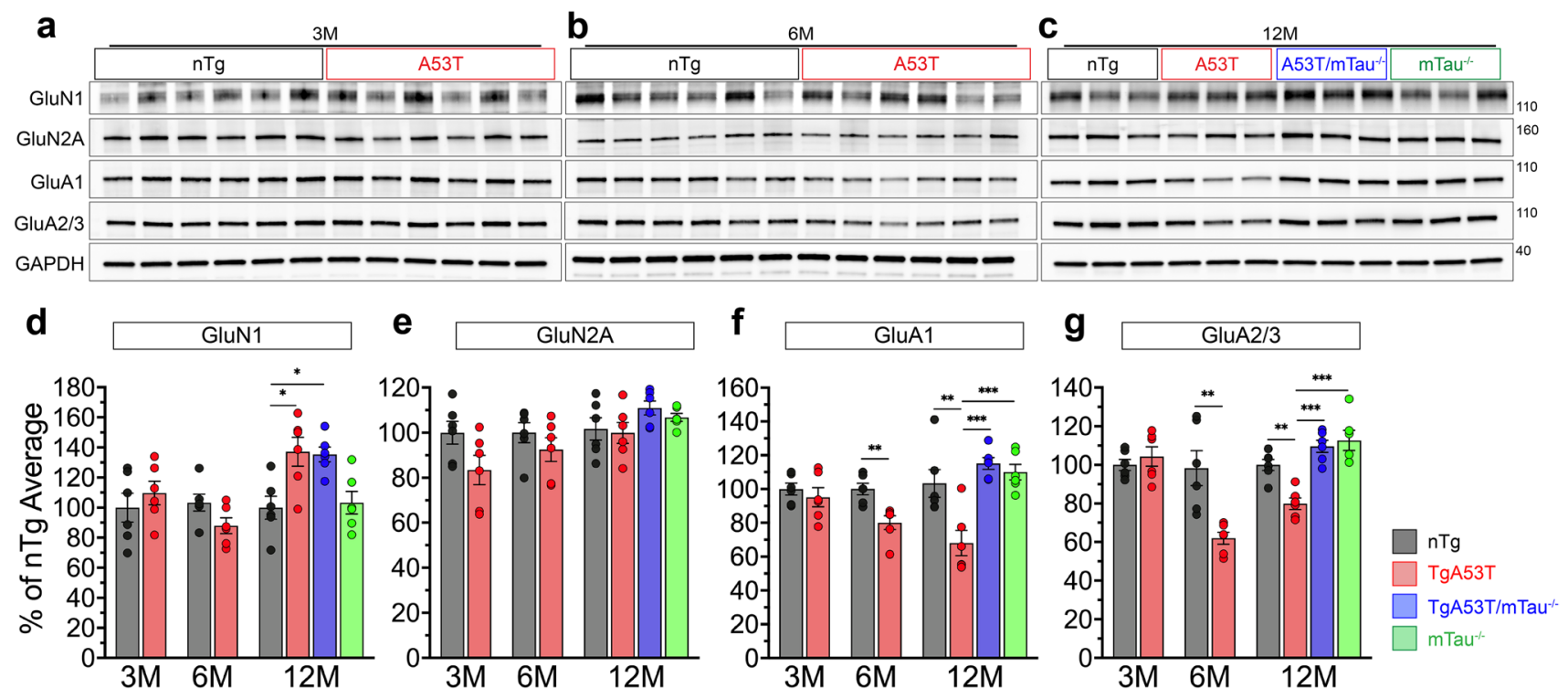

Fig. 8 Progressive loss of AMPA receptor subunits in the TgA53T is tau-dependent. Representative western blot images of hippocampal lysates of AMPA (GluA) and NMDA (GluN) receptor subunits at 3 (a), 6 (b), and 12 (c) months of age (3M, 6M, and 12M, respectively). d-g Densitometry of immunoblots for AMPA and NMDA receptor subunits at $3 \mathrm{M}, 6 \mathrm{M}$, and $12 \mathrm{M}$. For all, values were normalized to the average densitometric values of nTg samples within each gel. For 3M and 6M: unpaired $t$ test with Welch's correction. For $12 \mathrm{M}$ densitometry: one-way ANOVA with Tukey's posthoc analysis. 12M GluN1: $F_{(3,20)}=7.004, p=0.0021 .6 \mathrm{M}$ GluA1: $t=3.773, d f=9.679$,

NMDARs [63, 114]. It has recently been proposed that $\alpha \mathrm{S}$ oligomers causes cognitive deficits through a mechanism involving activation of the cellular prion protein $\left(\operatorname{PrP}^{\mathrm{C}}\right)$, Fyn, and GluN2B [31]. We, therefore, examined whether $\mathrm{PrP}^{\mathrm{C}}$-Fyn-GluN2B signaling is altered in the TgA53T model. In contrast to this recent study [31], TgA53T mice did not show increased $\mathrm{PrP}^{\mathrm{C}}$ expression, an established mechanism for mediating downstream increases in Fyn and GluN2B phosphorylation and activation [31, 114, 115] (Suppl. Figure 10, Online Resources). We also determined that Fyn phosphorylation and activation was not increased in the TgA53T model (Suppl. Figure 11a, b, Online Resources). The final output for pathological $\mathrm{PrP}^{\mathrm{C}}$ and Fyn signaling is increased NMDAR signaling through phosphorylation of GluN2B by Fyn. Consistent with the absence of increased $\operatorname{PrP}^{\mathrm{C}}$ expression and Fyn activation, phosphorylation-inducing activation of GluN2B was not detected in TgA53T mice with either intact or impaired cognition (Suppl. Figure 11c, $\mathrm{d}$, Online Resources). Taken together, our results do not support involvement of $\operatorname{PrP}^{\mathrm{C}}$-Fyn-GluN2B signaling in the memory deficits observed in TgA53T mice. Our conclusion is also supported a recent study, showing that $\mathrm{PrP}^{\mathrm{C}}$ neither binds nor mediates the toxic effects of $\alpha \mathrm{S}$ oligomers [58]. $p=0.0039 .12 \mathrm{M}$ GluA1: $F_{(3,20)}=11.55, p=0.0001 .6 \mathrm{M} \mathrm{GluA} 2 / 3$ : $t=3.801, d f=6.180, p=0.0085 .12 \mathrm{M} \mathrm{GluA} 2 / 3: F_{(3,20)}=16.21$, $p<0.0001$. $N=6$ animals/age/genotype. Compared to $\mathrm{nTg}$ mice, the NMDA receptor subunits are not decreased in $\operatorname{TgA}$ 53T mice at all ages tested (d, e). However, AMPA receptor subunits are significantly decreased starting at $6 \mathrm{M}$ in $\mathrm{TgA} 53 \mathrm{~T}$ mice compared to $\mathrm{nTg}$ $(\mathbf{f}, \mathbf{g})$. Significantly, the loss of AMPA receptor subunits are reversed in TgA53T/mTau ${ }^{-/-}$animals (f, g). $t$ test and one-way ANOVA: $* p<0.05, \quad * * p<0.01$, and $* * * p<0.001$. Error bars represent mean \pm SEM

\section{TgA53T mice exhibit progressive hippocampal inhibitory circuit remodeling}

Disruption of neuronal networks due to chronic network hyperactivity has been hypothesized to be a potential mechanism contributing to cognitive decline in neurodegenerative diseases [87], particularly via increased spontaneous epileptiform activity and compensatory remodeling of networks [20, 88, 107]. Thus, we asked if TgA53T mice exhibit evidence of hippocampal circuit remodeling typical of chronic network hyperactivity [85, 88]: loss of c-Fos positive dentate granule cells, ectopic neuropeptide Y (NPY) expression in the mossy fiber pathway and molecular layer of dentate gyrus, and reduction in calbindin in the granule cells of dentate gyrus and stratum radiatum of CA1 [79, 88, 95]. At 3 months of age, cognitively intact TgA53T mice display c-Fos, NPY, and calbindin staining indistinguishable from nTg mice (Fig. 9c, e; Suppl. Figure 12a, f, Online Resources). These results indicate that when mice display normal postsynaptic function and memory, hippocampal circuits have not been exposed to chronic network hyperactivity. At 6 months, two distinct populations of $\mathrm{TgA}$ 53T are observed: one displaying circuit remolding consistent with chronic network hyperactivity and another "intermediate" group without circuit remodeling (Fig. 9a, c, e; Suppl. Figure 12b-e, g, Online Resources). By 

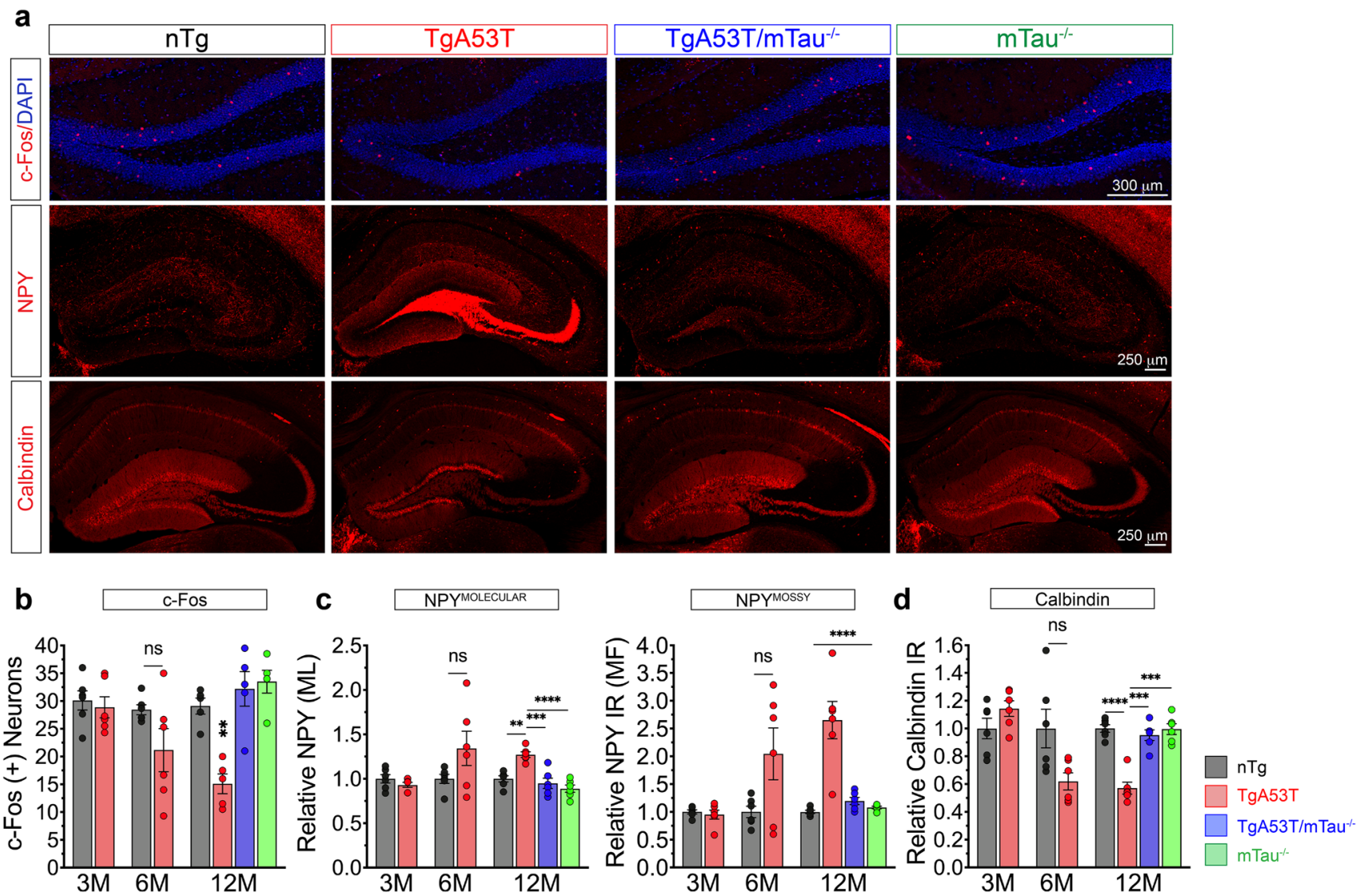

Fig. 9 Progressive alterations in inhibitory circuits in the dentate gyrus of TgA53T mice is tau-dependent and correlate with the onset of synaptic and memory deficits. a Representative images from dentate gyri and hippocampi of 12-month-old (12M) nTg, TgA53T, $\mathrm{TgA} 53 \mathrm{~T} / \mathrm{mTau}^{-/-}$, and $\mathrm{mTau}^{-/-}$mice. Similar images for 3-monthold $(3 \mathrm{M})$ and 6-month-old $(6 \mathrm{M})$ are shown in Supplementary Fig. 11 (Suppl. Figure 11, Online Resources). c-Fos scale bar $300 \mu \mathrm{m}$. NPY and calbindin scale bar $250 \mu \mathrm{m}$. Quantification of immunoreactivity (IR) via cell counting (b c-Fos) or densitometry (c NPY in the Molecular Layer "Molecular"; NPY in the Mossy Fiber pathway, "Mossy", and d calbindin) at 3M, 6M, and 12M. 6M: c-Fos: $U=7, p=0.0844$; NPY-molecular: $U=10, \quad p=0.2403$; NPY-Mossy: $U=11$,

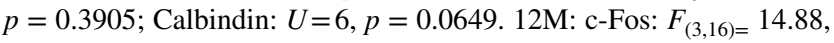

$p<0.0001$; NPY-molecular: $F_{(3,16)}=15.97, p<0.0001$; NPY-Mossy: $F_{(3,16)}=19.77, p<0.0001$; Calbindin: $F_{(3,16)}=19.03, p<0.0001 .3 \mathrm{M}$ analysis: unpaired $t$ test with Welch's correction. 6M analysis: MannWhitney $t$ test. 12M analysis: one-way ANOVA with Tukey's posthoc analysis. $N=6$ animals/age/genotype, $n=8$ sections/animal. In $3 \mathrm{M}$ $\mathrm{TgA} 53 \mathrm{~T}$ mice, the levels of synaptic activity markers are comparable to $\mathrm{nTg}$ mice. In $6 \mathrm{M} \mathrm{TgA53T}$ mice, two distinct populations of mice exist: TgA53T and TgA53T ${ }^{\mathrm{INT}}$ (analyzed in Suppl. Figure 11, Online Resources). All 12M TgA53T mice exhibit aberrant network remodeling which was reversed in $\mathrm{TgA} 53 \mathrm{~T} / \mathrm{mTau}^{-1-}$ mice. $t$ test and one-way ANOVA: $* p<0.05, * * p<0.01, * * * p<0.001$, and $* * * * p<0.0001$. $n s$ not significant, $I R$ immunoreactivity, $M L$ molecular layer, $M F$ mossy fiber. Error bars represent mean \pm SEM

12 months of age, all TgA53T mice show prominent network changes indicative of chronic epileptic activity (Fig. 9b-d; Suppl. Figure 12 h, Online Resources). Importantly, these age-dependent, $\alpha \mathrm{S}$-mediated alterations in hippocampal circuits are absent in the 12-month-old TgA53T/mTau ${ }^{-1-}$ mice. These results indicate that hippocampal network remodeling in the TgA53T model starts between 3 and 6 months of age, likely as a compensatory response to network hyperactivity.
The variability observed in 6-month-old $\mathrm{TgA}$ A3 $\mathrm{T}$ mice is consistent with animals undergoing a transition period. Furthermore, the TgA53T-linked inhibitory hippocampal circuit remodeling is absent in $\mathrm{TgA} 53 \mathrm{~T} / \mathrm{mTau}^{-/-}$animals, indicating that $h \alpha \mathrm{S}^{\mathrm{A} 53 \mathrm{~T}}$-associated network hyperactivity, along with progressive synaptic and memory deficits, requires endogenous tau expression. 


\section{Discussion}

Dementia associated with $\alpha$-synucleinopathy, particularly PDD and DLB, is one of the leading sources of global disability from neurological disorders [28, 53]. Currently, there are no effective therapies for managing PDD and DLB. Thus, understanding the cellular and molecular mechanisms of dementia in PDD and DLB will facilitate the development of new treatments. Previously, we proposed a model, where $\mathrm{h} \alpha \mathrm{S}^{\mathrm{A} 53 \mathrm{~T}}$ induces tau mislocalization to dendritic spines, leading to postsynaptic deficits in AMPAR signaling [110]. However, it was not known if these tau-related changes are directly causative for deficits in synaptic plasticity and learning and memory in the TgA53T mouse model. In our present study, we provide the first in vivo evaluation of the mechanistic relationships between $\alpha \mathrm{S}$ abnormalities, tau expression, synaptic function, and memory. Our data show that the removal of endogenous tau expression reverses a range of synaptic and memory impairments in $\mathrm{TgA}$ 53T mice. Furthermore, our results indicate that the effect of tau may be downstream or independent of potentially pathogenic $\alpha \mathrm{S}$ oligomeric or fibrillar species. Because TgA53T-associated deficits in synaptic function and learning and memory are not connected with hippocampal neurodegeneration, it is likely that tau regulates $h \alpha \mathrm{S}^{\mathrm{A} 53 \mathrm{~T}}$ alterations in synaptic physiology by perturbing neuronal function. In particular, our results indicate that tau-dependent loss of AMPAR function is an early event that is tightly correlated with LTP deficits, evidence of hippocampal network remodeling suggestive of chronic hyperactivity, and cognitive dysfunction in the TgA53T model.

A convergence of $\alpha \mathrm{S}$, tau, and $\mathrm{A} \beta$ pathologies has been observed in PDD and DLB patients with increased cognitive impairment, suggesting a mechanism for neuronal dysfunction in $\alpha$-synucleinopathies involving more than $\alpha \mathrm{S}$ pathology [23, 51]. Significantly, dementia, cortical and hippocampal $\alpha \mathrm{S}$ pathology, and tau pathology are often noted features of PD patients with A53T mutation in $\alpha \mathrm{S}[11,29,39,73$, 106]. In this study, we expand on the interaction between $\alpha \mathrm{S}$ and tau by showing that physiological tau expression independent contributes to neurophysiological and memory deficits in TgA53T mice. While we were not able to document accumulation of pathological tau oligomers, others have shown that pathological accumulation of tau oligomers in another TgA53T mouse model [34], suggesting that tau may act downstream of $\alpha \mathrm{S}$ pathology. Our results also add to the role of endogenous tau expression as a mediator of neuropathological phenotypes in AD models [52, 94, 95, 118]. The requirement of tau for memory deficits and the immunohistochemical markers of chronic epileptiform activity in the TgA53T model is reminiscent of studies in the hAPP-J20 transgenic mouse model of $\mathrm{AD}$, where loss of tau expression reversed memory deficits and epileptic activity [88, 94, 95]. In hAPP-J20 mice, chronic epileptiform activity is mechanistically linked to cognitive deficits. Thus, it is likely that network hyperactivity, as indicated by age-dependent remodeling of inhibitory networks in TgA53T mice, also contributes to memory deficits in the TgA53T mouse model. Significantly, another model of $\alpha$ S-dependent memory deficits (Thy 1-hoS: line 61) [45] also shows increased epileptic activity, which was partially dependent on endogenous mouse tau expression [79]. However, it is unknown if tau is required for memory deficits in the Thy $1-\mathrm{h} \alpha \mathrm{S}$ model or in other models of $\alpha \mathrm{S}$-dependent synaptic and memory deficits. The pathologic link between epileptic activity and memory deficits may be relevant for understanding DLB as both AD and DLB are associated with higher incidences of seizures and signs of seizure-like network hyperactivity $[9,75,78$, $79,88,95,107,117]$.

The progressive cognitive decline in $\mathrm{TgA} 53 \mathrm{~T}$ mice first observed at 6 months of age appears to correlate primarily with the loss of AMPAR expression leading to deficits in postsynaptic activity and LTP. Interestingly, TgA53T mice at this age point do not consistently display the molecular signature for chronic network hyperactivity of reductions in dentate granule cell c-Fos expression, increased ectopic NPY expression, and calbindin depletion in dentate granule cells, suggesting that the synaptic and memory deficits in the $\mathrm{TgA}$ 53 $\mathrm{T}$ model seem to precede inhibitory network remodeling. However, because network remodeling is a likely response to chronic and aberrant network hyperactivity [85-87], we propose that the onset of this epileptiform activity is coincident with other synaptic deficits. It will be of significant future interest to determine the causal relationship between synaptic deficits, epileptic activity, and memory deficits, as it has been studied in the hAPP-J20 model [97].

While several transgenic $A \beta$ and $\alpha S$ mouse models share a final common outcome of memory loss through impairments in synaptic and neural network function, the mechanistic details appear to differ. One hypothesis for $\mathrm{A} \beta$-mediated cognitive decline involves postsynaptic dysfunction via activation of the $\mathrm{PrP}^{\mathrm{C}}$-Fyn pathway, leading to phosphorylation and activation of the NMDAR subunit GluN2B, which, in turn, culminates in excitotoxicity and spine loss $[37,63,95,114]$. This pathway has also been recently implicated in memory loss associated with $\alpha$-synucleinopathies [31]. However, in our studies, we did not observe $\mathrm{PrP}^{\mathrm{C}}$-Fyn-GluN2B activation in TgA53T mice, indicating that $h \alpha \mathrm{S}^{\mathrm{A} 53 \mathrm{~T}}$ produces progressive postsynaptic and cognitive deficits through a mechanism independent of this pathway. Interestingly, in the hAPP-J 20 model of AD, which, like TgA53T model of $\alpha$-synucleinopathy, requires tau as a mediator of synaptic dysfunction and memory loss 
[94], $\operatorname{PrP}^{\mathrm{C}}$, and Fyn activation appears to be mechanistically disconnected as tau-dependent cognitive decline in hAPP$\mathrm{J} 20$ mice is unaffected by $\operatorname{PrP}^{\mathrm{C}}$ ablation [21]. Furthermore, this view is consistent with a recent report [58] showing that, in contrast to the findings of Ferreira et al. [30], $\operatorname{PrP}^{\mathrm{C}}$ does not mediate the detrimental effects of $\alpha \mathrm{S}$ oligomers. Our results suggest that synaptic and memory deficits in the TgA53T model appear to be independent of alterations in NMDAR but associated with decreased AMPAR subunit expression. Finally, consistent with the lack of Fyn-GluN2B activation, we do not observe a significant loss of postsynaptic structures in aged TgA53T mice.

Pathological $\alpha \mathrm{S}$ can spread throughout the central nervous system, including cortical and hippocampal neurons, in a hierarchal progression that appears to follow functionally connected regions $[12,13]$, raising the possibility that certain neurodegenerative processes in PD may be produced by abnormal network activity. Supporting this mechanistic view, studies link PDD and DLB with LNs in the hippocampal CA2/3 region [4, 42]. Here, we provide evidence, where pathogenic $\alpha \mathrm{S}$ causes reduced synaptic activity at specific excitatory synapses in the hippocampus, leading to deficits in AMPAR signaling and LTP. However, we also show that pathogenic h $\alpha \mathrm{S}^{\mathrm{A} 53 \mathrm{~T}}$ concurrently elicits aberrant excitatory activity as indicated by prominent compensatory remodeling of the inhibitory hippocampal circuits. One hypothesis to reconcile these seemingly contradictory observations is that depression of excitatory synaptic activity may be caused by a compensatory synaptic scaling mechanism reminiscent of the pro-excitatory effects of $A \beta$. For example, while acute oligomeric $\mathrm{A} \beta$ or $\alpha \mathrm{S}$ application has been shown to transiently increase AMAPAR and NMDAR on the neuronal surface $[31,98]$, prolonged $A \beta$ oligomer exposure decreases AMPAR and NMDAR and suppresses synaptic plasticity [49, 102].

In our study, deficits in postsynaptic function, LTP, and memory are selectively associated with the expression of $h \alpha \mathrm{S}^{\mathrm{A} 53 \mathrm{~T}}$. Since increased expression of $\alpha$ - or $\beta$-synucleins lead to presynaptic deficits $[81,110]$, we conclude that $\alpha \mathrm{S}$-associated presynaptic deficit is not sufficient to cause LTP and cognitive decline. However, memory deficits have been documented in other transgenic mouse models expressing $h \alpha \mathrm{S}^{\mathrm{WT}}$ or $\mathrm{h} \alpha \mathrm{S}^{\mathrm{A} 30 \mathrm{P}}$ under the Thy-1 promoter [45]. Thus, under appropriate circumstances, it is clear that multiple $\mathrm{h} \alpha \mathrm{S}$ variants can cause cognitive dysfunction. Currently, it is unknown if the postsynaptic deficits observed in our $\mathrm{TgA} 53 \mathrm{~T}$ animals are associated with memory deficits in these other TgWT or TgA30P mouse models. However, increased epileptic activity has been documented in the TgWT Thy 1-h $\alpha$ S model (line 61) [79], suggesting possible common mechanisms underlying $\alpha \mathrm{S}$-dependent synaptic and network deficits. We propose that a number of factors, including variations in transgene expression, background of mouse strains, housing conditions, and testing conditions and parameters could all contribute to the accumulation of toxic $\alpha \mathrm{S}$ species that cause of memory deficits in TgWT and $\mathrm{TgA} 30 \mathrm{P}$ models. It will be of significance in the future to determine if tau is required for memory deficits in multiple transgenic mouse models of $\alpha$-synucleinopathy.

Although synaptic loss is the major correlate for memory loss in AD patients $[27,99,100,111]$, clinical and pathological studies suggest that cognitive deficits in PDD/DLB occur in the absence of large-scale loss of hippocampal neurons [11, 46, 50, 55]. Furthermore, while the amount of tau pathology correlates with the severity of dementia [26], tau pathology per se is not as strongly linked to the incidence of dementia in PDD and DLB as $\alpha \mathrm{S}$ or A $\beta$ pathology [42, 50, 53, 54]. Significantly, the $M A P T H 1$ haplotype increases risk for PDD and DLB [40, 83]. Since the MAPT H1 haplotype is thought to increase tau expression [80], it is possible that basal tau expression, independent of tau pathology, contributes to $\alpha \mathrm{S}$-dependent memory impairments in humans.

Prior to our current study, it was previously unknown how pathologic and genetic observations associated with PDD and DLB are related to the development of deficits in synaptic plasticity that underlies cognitive dysfunction. We provide evidence that the TgA53T model exhibits progressive, tau-dependent, memory loss associated with postsynaptic AMPAR dysfunction in the absence of overt synaptic loss and hippocampal neurodegeneration. More importantly, our results suggest that endogenous tau is required for the specific synaptic and memory deficits observed in TgA53T mice. In addition, we propose that $h \alpha \mathrm{S}^{\mathrm{A} 53 \mathrm{~T}}$ causes taudependent synaptic alterations that lead to increased network hyperactivity that contribute to and exacerbate memory deficits (Suppl. Figure 13, Online Resources). Our results, combined with the previous studies in AD models, suggest that network hyperexcitability represents a novel therapeutic target for treating this driver of cognitive dysfunction in $\alpha$-synucleinopathies. Collectively, this study introduces a mechanism that identifies key proteins and mechanisms that could mediate the neuronal dysfunction underlying memory deficits in PDD and DLB. Ultimately, building a more complete picture of how pathologic $\alpha \mathrm{S}$ produces memory deficits is essential for developing novel therapeutic strategies for PDD and DLB.

Acknowledgements We thank Drs. Keith Vossel and Scott Vermilyea for their thoughtful discussion. We would also like to thank Dr. Mark Sanders of the University Imaging Centers at the University of Minnesota for his experimental and technical expertise and support.

Author contributions BS and MKL conceived the project and designed the experiments. BS and HM performed animal husbandry. BS, CG, $\mathrm{MAB}$, and AVS performed behavioral analysis. $\mathrm{AC}, \mathrm{CN}$, and $\mathrm{AA}$ preformed slice electrophysiology studies. BS and PJT performed electrophysiology on dissociated neuronal cultures. BS, MAS, and SEL performed biochemical analysis. BS, EO, and JM performed 
immunocytochemical analysis. MKL supervised the experiments. BS and MKL generated the figures and wrote the manuscript. AC, PJT, MAB, SEL, DL, and AA contributed to critical discussion and edited the manuscript. All authors discussed the results and commented on the manuscript.

Funding MKL is supported by Grants (R01NS086074, R01NS092093, R01NS108686, and R01AG062135) from the NIH. DL and MKL are co-supported by 1R21NS084007 from the NIH. SEL is supported by Grants (R00AG031293, R01AG044342, R01AG062135, and R01NS092918) from the National Institutes of Health (NIH), funds from the University of Minnesota Institute of Translational Neuroscience and gifts from the Strom and Moe families.

\section{Compliance with ethical standards}

Conflict of interest SEL is a scientific consultant for Acelot, Inc. and has no actual or potential conflict of interest in relation to this study. All other authors declare no conflict of interest.

Open Access This article is distributed under the terms of the Creative Commons Attribution 4.0 International License (http://creativeco mmons.org/licenses/by/4.0/), which permits unrestricted use, distribution, and reproduction in any medium, provided you give appropriate credit to the original author(s) and the source, provide a link to the Creative Commons license, and indicate if changes were made.

\section{References}

1. Aarsland D, Beyer MK, Kurz MW (2008) Dementia in Parkinson's disease. Curr Opin Neurol 21:676-682. https:// doi.org/10.1097/WCO.0b013e3283168df0

2. Aarsland D, Creese B, Politis M, Chaudhuri KR, Ffytche DH, Weintraub D et al (2017) Cognitive decline in Parkinson disease. Nat Rev Neurol 13:217-231. https://doi.org/10.1038/ nrneurol.2017.27

3. Abeliovich A, Schmitz Y, Fariñas I, Choi-Lundberg D, Ho W-H, Castillo PE et al (2000) Mice lacking $\alpha$-synuclein display functional deficits in the nigrostriatal dopamine system. Neuron 25:239-252. https://doi.org/10.1016/S0896-6273(00)80886 $-7$

4. Adamowicz DH, Roy S, Salmon DP, Galasko DR, Hansen LA, Masliah E et al (2017) Hippocampal $\alpha$-synuclein in dementia with Lewy bodies contributes to memory impairment and is consistent with spread of pathology. J Neurosci 37:1675-1684. https://doi.org/10.1523/JNEUROSCI.3047-16.2016

5. Amar F, Sherman MA, Rush T, Larson M, Boyle G, Chang L et al (2017) Amyloid- $\beta$ oligomer $A \beta * 56$ induces specific alterations of tau phosphorylation and neuronal signaling. Sci Signal. https://doi.org/10.1126/scisignal.aal2021

6. Antunes M, Biala G (2012) The novel object recognition memory: neurobiology, test procedure, and its modifications. Cogn Process 13:93-110. https://doi.org/10.1007/s10339-011-0430-z

7. Bach ME, Hawkins RD, Osman M, Kandel ER, Mayford M (1995) Impairment of spatial but not contextual memory in CaMKII mutant mice with a selective loss of hippocampal ltp in the range of the $\theta$ frequency. Cell 81:905-915. https://doi. org/10.1016/0092-8674(95)90010-1

8. Barnes CA (1979) Memory deficits associated with senescence: a neurophysiological and behavioral study in the rat. J Comp Physiol Psychol 93:74-104. https://doi.org/10.1037/h0077579
9. Beagle AJ, Darwish SM, Ranasinghe KG, La AL, Karageorgiou E, Vossel KA (2017) Relative incidence of seizures and myoclonus in Alzheimer's Disease, dementia with Lewy bodies, and frontotemporal dementia. J Alzheimers Dis 60:211-223. https:// doi.org/10.3233/JAD-170031

10. Bliss TVP, Collingridge GL (1993) A synaptic model of memory: long-term potentiation in the hippocampus. Nature 361:31. https://doi.org/10.1038/361031a0

11. Bougea A, Koros C, Stamelou M, Simitsi A, Papagiannakis N, Antonelou R et al (2017) Frontotemporal dementia as the presenting phenotype of p. A53T mutation carriers in the alpha-synuclein gene. Park Relat Disord 35:82-87. https://doi. org/10.1016/j.parkreldis.2016.12.002

12. Braak H, Del Tredici K (2008) Nervous system pathology in sporadic Parkinson disease. Neurology 70:1916-1925. https:// doi.org/10.1212/01.wnl.0000312279.49272.9f

13. Braak H, Tredici KD, Rüb U, de Vos RAI, Jansen Steur ENH, Braak E (2003) Staging of brain pathology related to sporadic Parkinson's disease. Neurobiol Aging 24:197-211. https://doi. org/10.1016/S0197-4580(02)00065-9

14. Burré J, Sharma M, Tsetsenis T, Buchman V, Etherton M, Südhof TC (2010) $\alpha$-Synuclein promotes SNARE-complex assembly in vivo and in vitro. Science 329:1663-1667. https://doi. org/10.1126/science.1195227

15. Burré J, Vivona S, Diao J, Sharma M, Brunger AT, Südhof TC (2013) Properties of native brain $\alpha$-synuclein. Nature 498:E4-E6. https://doi.org/10.1038/nature12125

16. Burré J, Sharma M, Südhof TC (2014) $\alpha$-Synuclein assembles into higher-order multimers upon membrane binding to promote SNARE complex formation. Proc Natl Acad Sci 111:E4274E4283. https://doi.org/10.1073/pnas.1416598111

17. Castillo-Carranza DL, Guerrero-Muñoz MJ, Sengupta U, Gerson JE, Kayed R (2018) $\alpha$-Synuclein oligomers induce a unique toxic tau strain. Biol Psychiatry 84:499-508. https://doi.org/10.1016/j. biopsych.2017.12.018

18. Chandra S, Gallardo G, Fernández-Chacón R, Schlüter OM, Südhof TC (2005) $\alpha$-Synuclein cooperates with CSP $\alpha$ in preventing neurodegeneration. Cell 123:383-396. https://doi.org/10.1016/j. cell.2005.09.028

19. Chesselet M-F, Richter F, Zhu C, Magen I, Watson MB, Subramaniam SR (2012) A progressive mouse model of Parkinson's disease: the Thy1-aSyn ("Line 61") mice. Neurotherapeutics 9:297-314. https://doi.org/10.1007/s13311-012-0104-2

20. Chin J, Palop JJ, Puoliväli J, Massaro C, Bien-Ly N, Gerstein H et al (2005) Fyn kinase induces synaptic and cognitive impairments in a transgenic mouse model of Alzheimer's disease. J Neurosci 25:9694-9703. https://doi.org/10.1523/JNEUR OSCI.2980-05.2005

21. Cissé M, Sanchez PE, Kim DH, Ho K, Yu G-Q, Mucke L (2011) Ablation of cellular prion protein does not ameliorate abnormal neural network activity or cognitive dysfunction in the J20 line of human amyloid precursor protein transgenic mice. J Neurosci 31:10427-10431. https://doi.org/10.1523/JNEUR OSCI.1459-11.2011

22. Colla E, Jensen PH, Pletnikova O, Troncoso JC, Glabe C, Lee MK (2012) Accumulation of toxic $\alpha$-synuclein oligomer within endoplasmic reticulum occurs in $\alpha$-synucleinopathy in vivo. J Neurosci 32:3301-3305. https://doi.org/10.1523/JNEUR OSCI.5368-11.2012

23. Colom-Cadena M, Gelpi E, Charif S, Belbin O, Blesa R, Martı MJ et al (2013) Confluence of $\alpha$-synuclein, tau, and $\beta$-amyloid pathologies in dementia with Lewy bodies. J Neuropathol Exp Neurol 72:10

24. Colom-Cadena M, Pegueroles J, Herrmann AG, Henstridge CM, Muñoz L, Querol-Vilaseca M et al (2017) Synaptic 
phosphorylated $\alpha$-synuclein in dementia with Lewy bodies. Brain 140:3204-3214. https://doi.org/10.1093/brain/awx275

25. Conrad CD, Galea LAM, Kuroda Y, McEwen BS (1996) Chronic stress impairs rat spatial memory on the Y maze, and this effect is blocked by tianeptine treatment. Behav Neurosci 110:1321-1334. https://doi.org/10.1037/0735-7044.110.6.1321

26. Coughlin DG, Xie SX, Liang M, Williams A, Peterson C, Weintraub D, McMillan CT, Wolk DA, Akhtar RS, Hurtig H, Coslett HB, Hamilton R, Siderowf A, Duda JE, Rascovsky K, Lee EB, Lee VMY, Grossman M, Trojanowski JQ, Irwin DJ (2018) Cognitive and pathological influences of tau pathology in lewy body disorders. Ann Neurol. https://doi.org/10.1002/ ana. 25392

27. de Wilde MC, Overk CR, Sijben JW, Masliah E (2016) Metaanalysis of synaptic pathology in Alzheimer's disease reveals selective molecular vesicular machinery vulnerability. Alzheimers Dement 12:633-644. https://doi.org/10.1016/j. jalz.2015.12.005

28. Dorsey ER, Elbaz A, Nichols E, Abd-Allah F, Abdelalim A, Adsuar JC et al (2018) Global, regional, and national burden of Parkinson's disease, 1990-2016: a systematic analysis for the Global Burden of Disease Study 2016. Lancet Neurol 17:939953. https://doi.org/10.1016/S1474-4422(18)30295-3

29. Duda JE, Giasson BI, Mabon ME, Miller DC, Golbe LI, Lee VM-Y et al (2002) Concurrence of $\alpha$-synuclein and tau brain pathology in the Contursi kindred. Acta Neuropathol (Berl) 104:7-11. https://doi.org/10.1007/s00401-002-0563-3

30. Fares M-B, Maco B, Oueslati A, Rockenstein E, Ninkina N, Buchman VL et al (2016) Induction of de novo $\alpha$-synuclein fibrillization in a neuronal model for Parkinson's disease. Proc Natl Acad Sci 113:E912-E921. https://doi.org/10.1073/ pnas. 1512876113

31. Ferreira DG, Temido-Ferreira M, Miranda HV, Batalha VL, Coelho JE, Szegö ÉM et al (2017) $\alpha$-synuclein interacts with PrPC to induce cognitive impairment through mGluR5 and NMDAR2B. Nat Neurosci 20:1569-1579. https://doi.org/10.1038/nn.4648

32. Fujiwara H, Hasegawa M, Dohmae N, Kawashima A, Masliah E, Goldberg MS et al (2002) $\alpha$-Synuclein is phosphorylated in synucleinopathy lesions. Nat Cell Biol 4:160-164. https://doi. org/10.1038/ncb748

33. George JM (2002) The synucleins. Genome Biol 3:reviews3002.1-reviews3002.6

34. Gerson JE, Farmer KM, Henson N, Castillo-Carranza DL, Carretero Murillo M, Sengupta U et al (2018) Tau oligomers mediate $\alpha$-synuclein toxicity and can be targeted by immunotherapy. Mol Neurodegener. https://doi.org/10.1186/s13024-018-0245-9

35. Giasson BI, Duda JE, Quinn SM, Zhang B, Trojanowski JQ, Lee VM-Y (2002) Neuronal $\alpha$-synucleinopathy with severe movement disorder in mice expressing A53T human $\alpha$-synuclein. Neuron 34:521-533. https://doi.org/10.1016/S0896-6273(02)00682 $-7$

36. Giasson BI, Forman MS, Higuchi M, Golbe LI, Graves CL, Kotzbauer PT et al (2003) Initiation and synergistic fibrillization of tau and alpha-synuclein. Science 300:636-640. https:// doi.org/10.1126/science.1082324

37. Gimbel DA, Nygaard HB, Coffey EE, Gunther EC, Laurén J, Gimbel ZA et al (2010) Memory impairment in transgenic Alzheimer mice requires cellular prion protein. J Neurosci 30:63676374. https://doi.org/10.1523/JNEUROSCI.0395-10.2010

38. Gispert S, Turco DD, Garrett L, Chen A, Bernard DJ, HammClement $\mathbf{J}$ et al (2003) Transgenic mice expressing mutant A53T human alpha-synuclein show neuronal dysfunction in the absence of aggregate formation. Mol Cell Neurosci 24:419-429. https://doi.org/10.1016/S1044-7431(03)00198-2
39. Golbe LI, Iorio GD, Bonavita V, Miller DC, Duvoisin RC (1990) A large kindred with autosomal dominant Parkinson's disease. Ann Neurol 27:276-282. https://doi.org/10.1002/ana.410270309

40. Goris A, Williams-Gray CH, Clark GR, Foltynie T, Lewis SJG, Brown J et al (2007) Tau and $\alpha$-synuclein in susceptibility to, and dementia in, Parkinson's disease. Ann Neurol 62:145-153. https ://doi.org/10.1002/ana.21192

41. Graham DR, Sidhu A (2010) Mice expressing the A53T mutant form of human alpha-synuclein exhibit hyperactivity and reduced anxiety-like behavior. J Neurosci Res 88:1777-1783. https://doi. org/10.1002/jnr.22331

42. Hall H, Reyes S, Landeck N, Bye C, Leanza G, Double K et al (2014) Hippocampal Lewy pathology and cholinergic dysfunction are associated with dementia in Parkinson's disease. Brain 137:2493-2508. https://doi.org/10.1093/brain/awu193

43. Harding AJ, Halliday GM (2001) Cortical Lewy body pathology in the diagnosis of dementia. Acta Neuropathol (Berl) 102:355363. https://doi.org/10.1007/s004010100390

44. Hashimoto M, Rockenstein E, Mante M, Mallory M, Masliah E (2001) $\beta$-Synuclein inhibits $\alpha$-synuclein aggregation: a possible role as an anti-Parkinsonian factor. Neuron 32:213-223. https:// doi.org/10.1016/S0896-6273(01)00462-7

45. Hatami A, Chesselet M-F (2015) Transgenic rodent models to study alpha-Synuclein pathogenesis, with a focus on cognitive deficits. In: Nguyen HHP, Cenci MA (eds) Behavioral neurobiology of Huntington's disease and Parkinson's disease. Springer, Berlin, pp 303-330

46. Hely MA, Reid WGJ, Adena MA, Halliday GM, Morris JGL (2008) The Sydney multicenter study of Parkinson's disease: the inevitability of dementia at 20 years. Mov Disord 23:837-844. https://doi.org/10.1002/mds.21956

47. Hoover BR, Reed MN, Su J, Penrod RD, Kotilinek LA, Grant MK et al (2010) Tau mislocalization to dendritic spines mediates synaptic dysfunction independently of neurodegeneration. Neuron 68:1067-1081. https://doi.org/10.1016/j.neuron.2010.11.030

48. Houlden H, Singleton AB (2012) The genetics and neuropathology of Parkinson's disease. Acta Neuropathol (Berl) 124:325338. https://doi.org/10.1007/s00401-012-1013-5

49. Hsieh H, Boehm J, Sato C, Iwatsubo T, Tomita T, Sisodia S et al (2006) AMPAR removal underlies A $\beta$-induced synaptic depression and dendritic spine loss. Neuron 52:831-843. https://doi. org/10.1016/j.neuron.2006.10.035

50. Irwin DJ, White MT, Toledo JB, Xie SX, Robinson JL, Van Deerlin V et al (2012) Neuropathologic substrates of Parkinson's disease dementia. Ann Neurol 72:587-598. https://doi.org/10.1002/ ana.23659

51. Irwin DJ, Lee VM-Y, Trojanowski JQ (2013) Parkinson's disease dementia: convergence of $\alpha$-synuclein, tau and amyloid- $\beta$ pathologies. Nat Rev Neurosci 14:626-636. https://doi.org/10.1038/ nrn3549

52. Ittner LM, Ke YD, Delerue F, Bi M, Gladbach A, van Eersel J et al (2010) Dendritic function of tau mediates amyloid- $\beta$ toxicity in Alzheimer's disease mouse models. Cell 142:387-397. https ://doi.org/10.1016/j.cell.2010.06.036

53. Jellinger KA, Korczyn AD (2018) Are dementia with Lewy bodies and Parkinson's disease dementia the same disease? BMC Med. https://doi.org/10.1186/s12916-018-1016-8

54. Kalaitzakis ME, Christian LM, Moran LB, Graeber MB, Pearce RKB, Gentleman SM (2009) Dementia and visual hallucinations associated with limbic pathology in Parkinson's disease. Park Relat Disord 15:196-204. https://doi.org/10.1016/j.parkreldis .2008.05.007

55. Kantarci K, Lesnick T, Ferman TJ, Przybelski SA, Boeve BF, Smith GE et al (2016) Hippocampal volumes predict risk of dementia with Lewy bodies in mild cognitive impairment. 
Neurology 87:2317-2323. https://doi.org/10.1212/WNL.00000 00000003371

56. Khan SS, LaCroix M, Boyle G, Sherman MA, Brown JL, Amar F et al (2018) Bidirectional modulation of Alzheimer phenotype by alpha-synuclein in mice and primary neurons. Acta Neuropathol (Berl) 136:589-605. https://doi.org/10.1007/s00401-018-1886-Z

57. Koprich JB, Kalia LV, Brotchie JM (2017) Animal models of $\alpha$-synucleinopathy for Parkinson disease drug development. Nat Rev Neurosci 18:515-529. https://doi.org/10.1038/nrn.2017.75

58. La Vitola P, Beeg M, Balducci C, Santamaria G, Restelli E, Colombo L et al (2019) Cellular prion protein neither binds to alpha-synuclein oligomers nor mediates their detrimental effects. Brain 142:249-254. https://doi.org/10.1093/brain/awy318

59. Larson ME, Lesné SE (2012) Soluble A $\beta$ oligomer production and toxicity. J Neurochem 120:125-139. https://doi.org/10.111 1/j.1471-4159.2011.07478.x

60. Larson ME, Sherman MA, Amar F, Nuvolone M, Schneider JA, Bennett DA et al (2012) The complex PrPc-Fyn couples human oligomeric A $\beta$ with pathological tau changes in Alzheimer's disease. J Neurosci 32:16857-16871. https://doi.org/10.1523/ JNEUROSCI.1858-12.2012

61. Larson ME, Greimel SJ, Amar F, LaCroix M, Boyle G, Sherman MA et al (2017) Selective lowering of synapsins induced by oligomeric $\alpha$-synuclein exacerbates memory deficits. Proc Natl Acad Sci 114:E4648-E4657. https://doi.org/10.1073/pnas.17046 98114

62. Lasagna-Reeves CA, Castillo-Carranza DL, Sengupta U, Sarmiento J, Troncoso J, Jackson GR et al (2012) Identification of oligomers at early stages of tau aggregation in Alzheimer's disease. FASEB J 26:1946-1959. https://doi.org/10.1096/fj.11-199851

63. Laurén J, Gimbel DA, Nygaard HB, Gilbert JW, Strittmatter SM (2009) Cellular prion protein mediates impairment of synaptic plasticity by amyloid- $\beta$ oligomers. Nature $457: 1128-1132$. https ://doi.org/10.1038/nature07761

64. Lavedan C (1998) The synuclein family. Genome Res 8:871-880. https://doi.org/10.1101/gr.8.9.871

65. Lee MK, Stirling W, Xu Y, Xu X, Qui D, Mandir AS et al (2002) Human $\alpha$-synuclein-harboring familial Parkinson's diseaselinked Ala-53-> Thr mutation causes neurodegenerative disease with $\alpha$-synuclein aggregation in transgenic mice. Proc Natl Acad Sci 99:8968-8973. https://doi.org/10.1073/pnas.132197599

66. Li W, West N, Colla E, Pletnikova O, Troncoso JC, Marsh L et al (2005) Aggregation promoting C-terminal truncation of $\alpha$-synuclein is a normal cellular process and is enhanced by the familial Parkinson's disease-linked mutations. Proc Natl Acad Sci 102:2162-2167. https://doi.org/10.1073/pnas.0406976102

67. Lim Y, Kehm VM, Li C, Trojanowski JQ, Lee VM-Y (2010) Forebrain overexpression of $\alpha$-synuclein leads to early postnatal hippocampal neuron loss and synaptic disruption. Exp Neurol 221:86-97. https://doi.org/10.1016/j.expneurol.2009.10.005

68. Lim Y, Kehm VM, Lee EB, Soper JH, Li C, Trojanowski JQ et al (2011) $\alpha$-Syn suppression reverses synaptic and memory defects in a mouse model of dementia with Lewy bodies. $\mathbf{J}$ Neurosci 31:10076-10087. https://doi.org/10.1523/JNEUR OSCI.0618-11.2011

69. Lindersson E, Beedholm R, Højrup P, Moos T, Gai W, Hendil $\mathrm{KB}$ et al (2004) Proteasomal inhibition by $\alpha$-synuclein filaments and oligomers. J Biol Chem 279:12924-12934. https://doi. org/10.1074/jbc.M306390200

70. Magen I, Fleming SM, Zhu C, Garcia EC, Cardiff KM, Dinh D et al (2012) Cognitive deficits in a mouse model of pre-manifest Parkinson's disease. Eur J Neurosci 35:870-882. https://doi.org /10.1111/j.1460-9568.2012.08012.x
71. Malinow R, Malenka RC (2002) AMPA receptor trafficking and synaptic plasticity. Annu Rev Neurosci 25:103-126. https://doi. org/10.1146/annurev.neuro.25.112701.142758

72. Malinow R, Mainen ZF, Hayashi Y (2000) LTP mechanisms: from silence to four-lane traffic. Curr Opin Neurobiol 10:352357. https://doi.org/10.1016/S0959-4388(00)00099-4

73. Markopoulou K, Dickson D, McComb R, Wszolek Z, Katechalidou L, Avery L et al (2008) Clinical, neuropathological and genotypic variability in SNCA A53T familial Parkinson's disease. Acta Neuropathol (Berl) 116:25-35. https://doi. org/10.1007/s00401-008-0372-4

74. Maroteaux L, Scheller RH (1991) The rat brain synucleins; family of proteins transiently associated with neuronal membrane. Mol Brain Res 11:335-343. https://doi.org/10.1016/0169328X(91)90043-W

75. Martinez-Losa M, Tracy TE, Ma K, Verret L, Clemente-Perez A, Khan AS et al (2018) Nav1.1-overexpressing interneuron transplants restore brain rhythms and cognition in a mouse model of Alzheimer's disease. Neuron 98:75-89.e5. https://doi. org/10.1016/j.neuron.2018.02.029

76. McKernan MG, Shinnick-Gallagher P (1997) Fear conditioning induces a lasting potentiation of synaptic currents in vitro. Nature 390:607-611. https://doi.org/10.1038/37605

77. Miller EC, Teravskis PJ, Dummer BW, Zhao X, Huganir RL, Liao D (2014) Tau phosphorylation and tau mislocalization mediate soluble A $\beta$ oligomer-induced AMPA glutamate receptor signaling deficits. Eur J Neurosci 39:1214-1224. https://doi. org/10.1111/ejn.12507

78. Minkeviciene R, Rheims S, Dobszay MB, Zilberter M, Hartikainen J, Fulop L et al (2009) Amyloid $\beta$-induced neuronal hyperexcitability triggers progressive epilepsy. J Neurosci 29:34533462. https://doi.org/10.1523/JNEUROSCI.5215-08.2009

79. Morris M, Sanchez PE, Verret L, Beagle AJ, Guo W, Dubal $D$ et al (2015) Network dysfunction in $\alpha$-synuclein transgenic mice and human Lewy body dementia. Ann Clin Transl Neurol 2:1012-1028. https://doi.org/10.1002/acn3.257

80. Myers AJ, Pittman AM, Zhao AS, Rohrer K, Kaleem M, Marlowe L et al (2007) The MAPT H1c risk haplotype is associated with increased expression of tau and especially of 4 repeat containing transcripts. Neurobiol Dis 25:561-570. https://doi.org/10.1016/j. nbd.2006.10.018

81. Nemani VM, Lu W, Berge V, Nakamura K, Onoa B, Lee MK et al (2010) Increased expression of $\alpha$-synuclein reduces neurotransmitter release by inhibiting synaptic vesicle reclustering after endocytosis. Neuron 65:66-79. https://doi.org/10.1016/j.neuro n.2009.12.023

82. Obeso JA, Rodriguez-Oroz MC, Goetz CG, Marin C, Kordower JH, Rodriguez M et al (2010) Missing pieces in the Parkinson's disease puzzle. Nat Med 16:653-661. https://doi.org/10.1038/ nm. 2165

83. Orme T, Guerreiro R, Bras J (2018) The genetics of dementia with Lewy bodies: current understanding and future directions. Curr Neurol Neurosci Rep. https://doi.org/10.1007/s1191 0-018-0874-y

84. Paleologou KE, Kragh CL, Mann DMA, Salem SA, Al-Shami R, Allsop D et al (2009) Detection of elevated levels of soluble $\alpha$-synuclein oligomers in post-mortem brain extracts from patients with dementia with Lewy bodies. Brain 132:1093-1101. https://doi.org/10.1093/brain/awn349

85. Palop JJ, Mucke L (2010) Synaptic depression and aberrant excitatory network activity in Alzheimer's disease: two faces of the same coin? NeuroMol Med 12:48-55. https://doi.org/10.1007/ s12017-009-8097-7 
86. Palop JJ, Mucke L (2016) Network abnormalities and interneuron dysfunction in Alzheimer disease. Nat Rev Neurosci 17:777-792. https://doi.org/10.1038/nrn.2016.141

87. Palop JJ, Chin J, Mucke L (2006) A network dysfunction perspective on neurodegenerative diseases. Nature 443:768-773. https://doi.org/10.1038/nature05289

88. Palop JJ, Chin J, Roberson ED, Wang J, Thwin MT, Bien-Ly N et al (2007) Aberrant excitatory neuronal activity and compensatory remodeling of inhibitory hippocampal circuits in mouse models of Alzheimer's disease. Neuron 55:697-711. https://doi. org/10.1016/j.neuron.2007.07.025

89. Palop JJ, Mucke L, Roberson ED (2011) Quantifying biomarkers of cognitive dysfunction and neuronal network hyperexcitability in mouse models of Alzheimer's disease: depletion of calciumdependent proteins and inhibitory hippocampal remodeling. In: Roberson ED (ed) Alzheimer's disease and frontotemporal dementia: methods and protocols. Humana Press, Totowa, pp 245-262

90. Paumier KL, Sukoff Rizzo SJ, Berger Z, Chen Y, Gonzales C, Kaftan E et al (2013) Behavioral characterization of A53T mice reveals early and late stage deficits related to Parkinson's disease. PLoS One 8:e70274. https://doi.org/10.1371/journal.pone.00702 74

91. Phillips RG, LeDoux JE (1992) Differential contribution of amygdala and hippocampus to cued and contextual fear conditioning. Behav Neurosci 106:274-285. https://doi. org/10.1037/0735-7044.106.2.274

92. Poewe W, Seppi K, Tanner CM, Halliday GM, Brundin P, Volkmann J et al (2017) Parkinson disease. Nat Rev Dis Primer 3:17013. https://doi.org/10.1038/nrdp.2017.13

93. Polymeropoulos MH, Lavedan C, Leroy E, Ide SE, Dehejia A, Dutra A et al (1997) Mutation in the $\alpha$-synuclein gene identified in families with Parkinson's disease. Science 276:2045-2047. https://doi.org/10.1126/science.276.5321.2045

94. Roberson ED, Scearce-Levie K, Palop JJ, Yan F, Cheng IH, Wu $\mathrm{T}$ et al (2007) Reducing endogenous tau ameliorates amyloid $\beta$-induced deficits in an Alzheimer's disease mouse model. Science 316:750-754. https://doi.org/10.1126/science.1141736

95. Roberson ED, Halabisky B, Yoo JW, Yao J, Chin J, Yan F et al (2011) Amyloid- $\beta /$ Fyn-induced synaptic, network, and cognitive impairments depend on tau levels in multiple mouse models of Alzheimer's disease. J Neurosci 31:700-711. https://doi. org/10.1523/JNEUROSCI.4152-10.2011

96. Samuel F, Flavin WP, Iqbal S, Pacelli C, Sri Renganathan SD, Trudeau L-E et al (2016) Effects of Serine 129 phosphorylation on $\alpha$-synuclein aggregation, membrane association, and internalization. J Biol Chem 291:4374-4385. https://doi.org/10.1074/ jbc.M115.705095

97. Sanchez PE, Zhu L, Verret L, Vossel KA, Orr AG, Cirrito JR et al (2012) Levetiracetam suppresses neuronal network dysfunction and reverses synaptic and cognitive deficits in an Alzheimer's disease model. Proc Natl Acad Sci 109:E2895-E2903. https:// doi.org/10.1073/pnas.1121081109

98. Sanchez-Mejia RO, Newman JW, Toh S, Yu G-Q, Zhou Y, Halabisky B et al (2008) Phospholipase A2 reduction ameliorates cognitive deficits in a mouse model of Alzheimer's disease. Nat Neurosci 11:1311-1318. https://doi.org/10.1038/nn.2213

99. Scheff SW, Price DA, Schmitt FA, Mufson EJ (2006) Hippocampal synaptic loss in early Alzheimer's disease and mild cognitive impairment. Neurobiol Aging 27:1372-1384. https://doi. org/10.1016/j.neurobiolaging.2005.09.012

100. Selkoe DJ (2002) Alzheimer's disease is a synaptic failure. Science 298:789-791. https://doi.org/10.1126/science.1074069

101. Sengupta U, Guerrero-Muñoz MJ, Castillo-Carranza DL, Lasagna-Reeves CA, Gerson JE, Paulucci-Holthauzen AA et al (2015) Pathological interface between oligomeric alpha-synuclein and tau in synucleinopathies. Biol Psychiatry 78:672-683. https:// doi.org/10.1016/j.biopsych.2014.12.019

102. Shankar GM, Bloodgood BL, Townsend M, Walsh DM, Selkoe DJ, Sabatini BL (2007) Natural oligomers of the alzheimer amyloid- $\beta$ protein induce reversible synapse loss by modulating an NMDA-type glutamate receptor-dependent signaling pathway. J Neurosci 27:2866-2875. https://doi.org/10.1523/JNEUR OSCI.4970-06.2007

103. Sherman MA, LaCroix M, Amar F, Larson ME, Forster C, Aguzzi A et al (2016) Soluble conformers of $A \beta$ and tau alter selective proteins governing axonal transport. J Neurosci 36:9647-9658. https://doi.org/10.1523/JNEUROSCI.1899-16.2016

104. Spillantini MG, Schmidt ML, Lee VM-Y, Trojanowski JQ, Jakes R, Goedert M (1997) $\alpha$-Synuclein in Lewy bodies. Nature 388:839-840. https://doi.org/10.1038/42166

105. Spillantini MG, Anthony Crowther R, Jakes R, Cairns NJ, Lantos PL, Goedert M (1998) Filamentous $\alpha$-synuclein inclusions link multiple system atrophy with Parkinson's disease and dementia with Lewy bodies. Neurosci Lett 251:205-208. https://doi. org/10.1016/S0304-3940(98)00504-7

106. Spira PJ, Sharpe DM, Halliday G, Cavanagh J, Nicholson GA (2001) Clinical and pathological features of a parkinsonian syndrome in a family with an Ala53Thr $\alpha$-synuclein mutation. Ann Neurol 49:313-319. https://doi.org/10.1002/ana.67

107. Sun B, Halabisky B, Zhou Y, Palop JJ, Yu G, Mucke L et al (2009) Imbalance between GABAergic and glutamatergic transmission impairs adult neurogenesis in an animal model of Alzheimer's disease. Cell Stem Cell 5:624-633. https://doi. org/10.1016/j.stem.2009.10.003

108. Sunyer B, Patil S, Höger H, Lubec G (2007) Barnes maze, a useful task to assess spatial reference memory in the mice. Protoc Exch. https://doi.org/10.1038/nprot.2007.390

109. Taglialatela G, Hogan D, Zhang W-R, Dineley KT (2009) Intermediate- and long-term recognition memory deficits in $\mathrm{Tg} 2576$ mice are reversed with acute calcineurin inhibition. Behav Brain Res 200:95-99. https://doi.org/10.1016/j.bbr.2008.12.034

110. Teravskis PJ, Covelo A, Miller EC, Singh B, Martell-Martínez HA, Benneyworth MA et al (2018) A53T mutant alpha-synuclein induces tau-dependent postsynaptic impairment independently of neurodegenerative changes. J Neurosci 38:9754-9767. https ://doi.org/10.1523/JNEUROSCI.0344-18.2018

111. Terry RD, Masliah E, Salmon DP, Butters N, DeTeresa R, Hill $R$ et al (1991) Physical basis of cognitive alterations in Alzheimer's disease: synapse loss is the major correlate of cognitive impairment. Ann Neurol 30:572-580. https://doi.org/10.1002/ ana.410300410

112. Thomas B, Mandir AS, West N, Liu Y, Andrabi SA, Stirling W et al (2011) Resistance to MPTP-neurotoxicity in $\alpha$-synuclein knockout mice is complemented by human $\alpha$-synuclein and associated with increased $\beta$-synuclein and Akt activation. PLoS One 6:e16706. https://doi.org/10.1371/journal.pone.0016706

113. Tucker KL, Meyer M, Barde Y-A (2001) Neurotrophins are required for nerve growth during development. Nat Neurosci 4:29-37. https://doi.org/10.1038/82868

114. Um JW, Nygaard HB, Heiss JK, Kostylev MA, Stagi M, Vortmeyer A et al (2012) Alzheimer amyloid- $\beta$ oligomer bound to postsynaptic prion protein activates Fyn to impair neurons. Nat Neurosci 15:1227-1235. https://doi.org/10.1038/nn.3178

115. Um JW, Kaufman AC, Kostylev M, Heiss JK, Stagi M, Takahashi $\mathrm{H}$ et al (2013) Metabotropic glutamate receptor 5 is a coreceptor for alzheimer $\mathrm{A} \beta$ oligomer bound to cellular prion protein. Neuron 79:887-902. https://doi.org/10.1016/j.neuron.2013.06.036

116. Unger EL, Eve DJ, Perez XA, Reichenbach DK, Xu Y, Lee MK et al (2006) Locomotor hyperactivity and alterations in dopamine neurotransmission are associated with overexpression of A53T 
mutant human $\alpha$-synuclein in mice. Neurobiol Dis 21:431-443. https://doi.org/10.1016/j.nbd.2005.08.005

117. Verret L, Mann EO, Hang GB, Barth AMI, Cobos I, Ho K et al (2012) Inhibitory interneuron deficit links altered network activity and cognitive dysfunction in Alzheimer model. Cell 149:708721. https://doi.org/10.1016/j.cell.2012.02.046

118. Vossel KA, Zhang K, Brodbeck J, Daub AC, Sharma P, Finkbeiner $S$ et al (2010) Tau reduction prevents $A \beta$-induced defects in axonal transport. Science 330:198. https://doi.org/10.1126/ science. 1194653
119. Zhuang X, Oosting RS, Jones SR, Gainetdinov RR, Miller GW, Caron MG et al (2001) Hyperactivity and impaired response habituation in hyperdopaminergic mice. Proc Natl Acad Sci 98:1982-1987. https://doi.org/10.1073/pnas.98.4.1982

Publisher's Note Springer Nature remains neutral with regard to jurisdictional claims in published maps and institutional affiliations.

\section{Affiliations}

\section{Balvindar Singh ${ }^{1,2} \cdot$ Ana Covelo $^{3} \cdot$ Héctor Martell-Martínez $^{3} \cdot$ Carmen Nanclares $^{3} \cdot$ Mathew A. Sherman $^{3}$. Emmanuel Okematti ${ }^{3}$. Joyce Meints ${ }^{3}$. Peter J. Teravskis ${ }^{3}$. Christopher Gallardo ${ }^{4}$. Alena V. Savonenko ${ }^{9}$. Michael A. Benneyworth ${ }^{3,5,6}$. Sylvain E. Lesné ${ }^{3,5,7} \cdot$ Dezhi Liao $^{3,5} \cdot$ Alfonso Araque $^{3,5} \cdot$ Michael K. Lee $^{3,5,8}$ (1)}

1 Medical Scientist Training Program, University of Minnesota Medical School, 420 Delaware Street SE, Minneapolis, MN 55455, USA

2 Graduate Program in Neuroscience, University of Minnesota Medical School, 420 Delaware Street SE, Minneapolis, MN 55455, USA

3 Department of Neuroscience, University of Minnesota Medical School, 420 Delaware Street SE, Minneapolis, MN 55455, USA

4 Graduate Program in Pharmacology, University of Minnesota Medical School, 420 Delaware Street SE, Minneapolis, MN 55455, USA

5 Institute for Translational Neuroscience, University of Minnesota Medical School, 420 Delaware Street SE, Minneapolis, MN 55455, USA
6 Mouse Behavior Core, University of Minnesota Medical School, 420 Delaware Street SE, Minneapolis, MN 55455, USA

7 N. Budd Grossman Center for Memory Research and Care, University of Minnesota Medical School, 420 Delaware Street SE, Minneapolis, MN 55455, USA

8 Geriatric Research Education and Clinical Center, Minneapolis Veterans Affairs Health Care System, University of Minnesota Medical School, 420 Delaware Street SE, Minneapolis, MN 55455, USA

9 Department of Pathology, Johns Hopkins University School of Medicine, 733 N Broadway, Baltimore, MD 21205, USA 